Portland State University

PDXScholar

$5-1-1981$

\title{
A Comparison of Boone-Prescott Content and Sequence Analysis Data of Poorly and Highly Rated Clinician-Client Interactive Skills
}

Kathleen M. Noonan

Portland State University

Follow this and additional works at: https://pdxscholar.library.pdx.edu/open_access_etds

Part of the Communication Commons, and the Speech Pathology and Audiology Commons Let us know how access to this document benefits you.

Recommended Citation

Noonan, Kathleen M., "A Comparison of Boone-Prescott Content and Sequence Analysis Data of Poorly and Highly Rated Clinician-Client Interactive Skills" (1981). Dissertations and Theses. Paper 3064. https://doi.org/10.15760/etd.3057

This Thesis is brought to you for free and open access. It has been accepted for inclusion in Dissertations and Theses by an authorized administrator of PDXScholar. Please contact us if we can make this document more accessible: pdxscholar@pdx.edu. 
AN ABSTRACT OF THE THESIS OF Kathleen M. Noonan for the Master of Science in Speech Communication, with an emphasis in Speech Pathology/ Audiology, presented May 1, 1981.

Title: A Comparison of Boone-Prescott Content and Sequence Analysis Data of Poorly and Highly Rated Clinician-Client Interactive Skills.

APPROVED BY MEMBERS OF THE THESIS COMMITTEE:

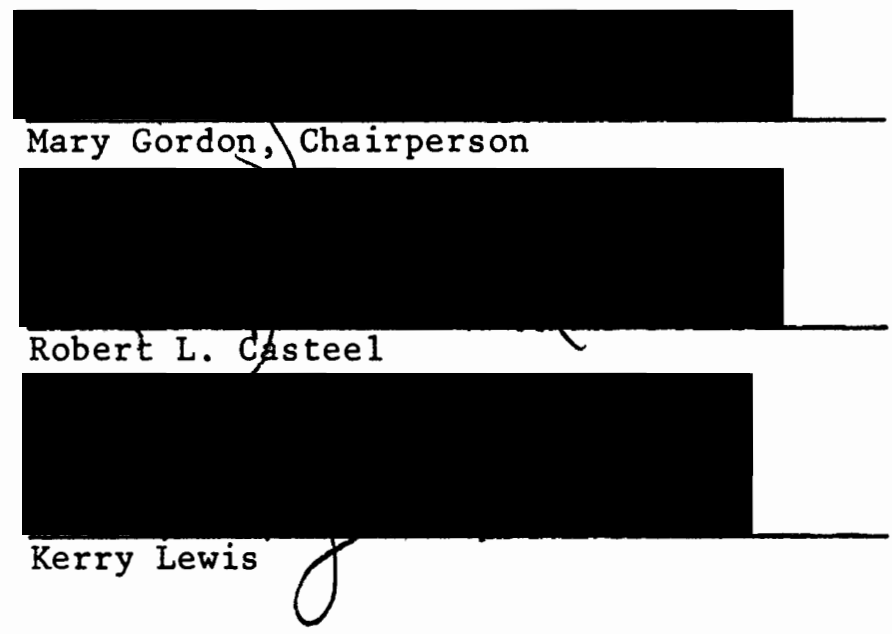

One of the qualifications for being a competent speech and language clinician is to be skilled in interactional procedures within a clinic setting. A clinician's interactional skills are developed through training whereby one participates in several clinical settings with clients displaying a variety of speech, language and hearing disorders. Various evaluation methods, both subjective and objective, have been utilized in guiding the clinician towards interactional 
competency.

Interactional analysis systems have been designed to provide more objective feedback. The Boone-Prescott Content and Sequence Analysis System $(\underline{B-P})$ is one of several such systems. Although this system has been found to be an asset towards evaluating the clinic session (Boone and Prescott, $1972_{b}$ ), information is lacking as to how the data from the parameters of the B-P Scoring Form reflect the quality of a clinician's interactive skills. Hence, this investigator sought to answer the following question: How do $\underline{B-P}$ data compare for clinicians who have been highly rated subjectively with those who have been less favorably rated subjectively by supervisors?

To proceed with the study, two supervisors, reflecting a behavioralistic point of view, chose subjectively from a group of thirty five-minute videotaped sessions, ten sessions in which student clinicians were demonstrating the poorest interactive skills (Group I) and ten sessions in which student clinicians were demonstrating the best clinical interactive skills (Group II). Following the supervisors' decision, each tape was analyzed using the $\underline{B-P}$.

Results reflect whether significant differences were demonstrated between groups for the parameters listed on the Revised BoonePrescott Scoring Form. Results indicated much variability between and within groups for many of the scores; consequently few statistically significant differences were found between groups.

A11 categories, with the exception of Category 9 (Good Self Evaluative) and Category 10 (Bad Self Evaluative), were used by the client subjects. Results for the categories indicated the higher 
rated clinicians significantly used a lesser percentage of explanation and description for clinic tasks (Category 1), more models and instructions (Category 2), less socializations (Category 5), and elicited more and a higher percentage of correct responses from their clients (Category 6) than did the poorer rated clinicians.

No statistically significant difference was found between groups for the clinician and client response totals; however, an approach towards significant differences was noted $(p<.10)$. For the clinician Total Response section, higher rated clinicians tended to use a lower percentage of total responses than the poorer clinicians. Reciprocally, the clients of the higher rated clinicians responded more than clients of the poorer rated clinicians. For the Clinician/Client Total Response section, the higher rated sessions tended to have more total interactions than the poorer rated sessions.

A statistically significant difference was found for only one ratio score, the Socialization Ratio, in which the higher rated clinicians had significantly less irrelevant responses than the poorly rated clinicians. Trends toward significance $(p<10)$ were noted for the remaining ratio scores. Clients of highly rated clinicians emitted a higher percentage of correct responses and a lower percentage of incorrect responses. Clients of highly rated clinicians tended to respond more appropriately than clients of poorly rated clinicians. Also, the highly rated clinicians tended to control client inappropriate responses and returned their attention back to the clinical task more often than the poorly rated clinicians.

Results indicated highly rated clinicians elicited statistically 
significantly more responses from their clients per minute than did poorly rated clinicians.

Although few sections revealed statistically significant differences between groups, results provide a guideline for more appropriate interactive behavior as demonstrated by the highly rated clinicians which is thought to be an asset for future supervisors and clinicians when evaluating clinical interaction skills. 
A COMPARISON OF BOONE-PRESCOTT CONTENT AND SEQUENCE ANALYSIS DATA OF POORLY AND HIGHLY RATED CLINICIAN-CLIENT INTERACTIVE SKILLS

by

KATHLEEN M. NOONAN

A thesis submitted in partial fulfillment of the requirements for the degree of

MASTER OF SCIENCE IN SPEECH COMMUNICATION:

with an emphasis in

SPEECH PATHOLOGY/AUDIOLOGY

Portland State University

1981 
TO THE OFFICE OF GRADUATE STUDIES AND RESEARCH:

The members of the Committee approve the thesis of Kathleen $M$. Noonan presented May 1, 1981.

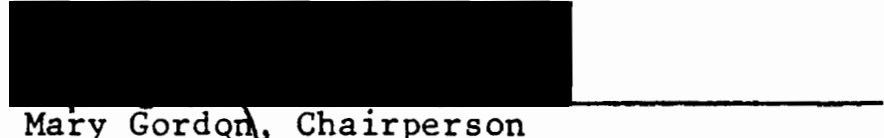
Mary Gordan, Chairperson
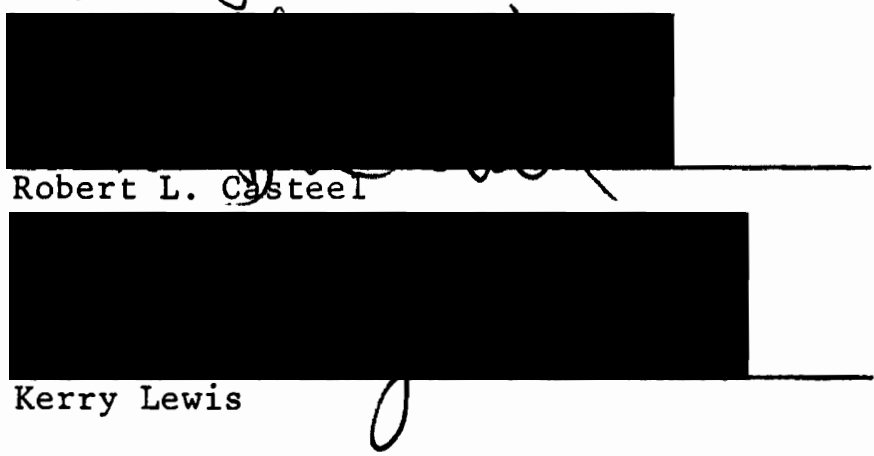

APPROVED :

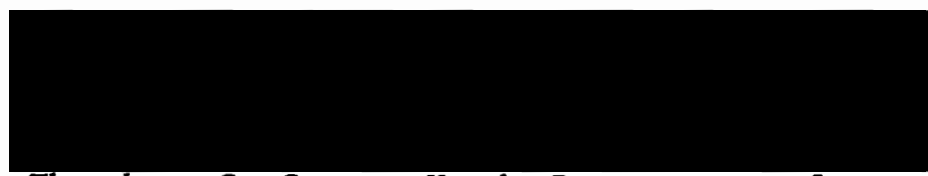

Theodore G. Grove, Head, Department of Speech Communication

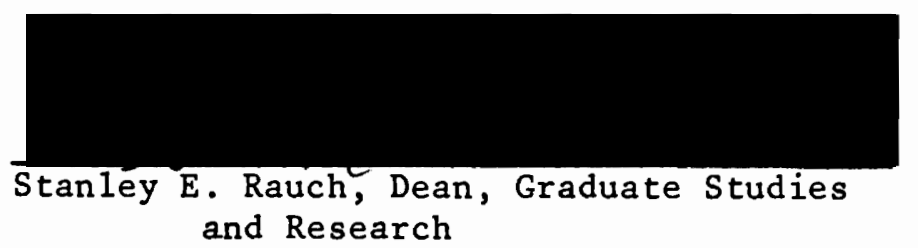


DEDICATION

To Mom and Dad 


\section{ACKNOWLEDGEMENTS}

At last my thoughts can be expressed to all the many special people to whom I owe so much thanks. Without your help the completion of graduate school-let alone a thesis-would have been only a dream.

First, my deepest appreciation to the faculty for your professional, yet personal, guidance and help, molding me into the more competent clinician I feel I have become. Dr. Ted Grove, thanks for explaining a statistical procedure that I could understand and use for my thesis. Dr. Kaplan, thank you for your helpful comments as a member of my thesis committee. I hope you will find the $\underline{B-P}$ beneficial to your students. Dr. E., many thanks for your help and suggestions in my clinical practicums. Joan McMahon, thank you for all your clinical suggestions, especially during student teaching. Your go-get-'em attitude toward clinical work has been an inspiration to me! Shari Kazdoy, thanks for your input. How could I have learned so much about the hearing impaired without your personal example, explanations and suggestions for management. Margaret Callahan, you are a super example to follow. I learned a lot on our travels through the Oregon countryside. Kerry Lewis, my thanks to you for your guidance as a clinical supervisor and for your input on my thesis. A simple chat in the halls or in your office about my concerns was always helpful.

Dr. Casteel, no words express my gratitude for your help on my thesis and throughout the two years as my advisor. You have been more than an advisor. You have been a friend, a motivator, a "father" and 
a professional model. Your concern not only for my professional growth but also for me as a person will always be remembered.

Mary Gordon, you have played a big role in helping me to improve as a clinician. You have a special way with people; and as my instructor, supervisor, friend and thesis director, you reflected this quality. I cannot possibly express my appreciation to you for all your help. Your calmness, incitefulness and simple explanations helped pull me off the ceiling many times! You are certainly an example to follow. Thank you again.

A special thanks to all my friends at Portland State, especially to Solidad Chavarria, Jennie Choong, Jean Goodling, Jackie Hicks, Doug Peterson, Mel Valenciano and Michelle Trembley. Our tight friendship helped to lighten the load of graduate school. I'11 always have fond memories not only for our study sessions and clinic discussions but also for our fun parties. What would we do without friends! Arti Helmer, my thanks to you for always lending your ear to the many experiences I've had these last two years.

John O'Keeffe, soon you won't see me studying all the time. (Unbelievable, huh?!) Always know how grateful I am to you for your patience, understanding and moral support over the last two years.

Above al1, I say thank you to the backbone of my life. Yes, it is you, Mom and Dad, and Mary, Mo and Don. Through your love and support I am where I am today. I am so blessed to have such a special family.

And thank you, God. I promise I won't talk about the B-P any more! 
TABLE OF CONTENTS

Page

ACKNOWLEDGEMENTS . . . . . . . . . . . . . . . . . . . . iv

LIST OF TABLES . . . . . . . . . . . . . . . . . . . . . . . ix

LIST OF FIGURES . . . . . . . . . . . . . . . . . . . . $\mathrm{x}$

CHAPTER

I INTRODUCTION AND PURPOSE . . . . . . . . . . . . . 1

Introduction . . . . . . . . . . . . . . 1

Statement of Purpose . . . . . . . . . . 3

II REVIEW OF THE LITERATURE . . . . . . . . . . . . 5

Roles of the Supervisor . . . . . . . . . 5

Clinical Observation . . . . . . . . . . 8

Clinical Evaluation ............. . 8

Interactional Analysis Systems . . . . . . . . 11

Summary and Implications . . . . . . . . 18

III METHODS AND PROCEDURES . . . . . . . . . . . . . 20

Methods . . . . . . . . . . . . . 20

Subjects

Instrumentation

Investigator Reliability

Test Setting

Procedures . . . . . . . . . . . . . 26

Boone-Prescott Behavioral Recording 


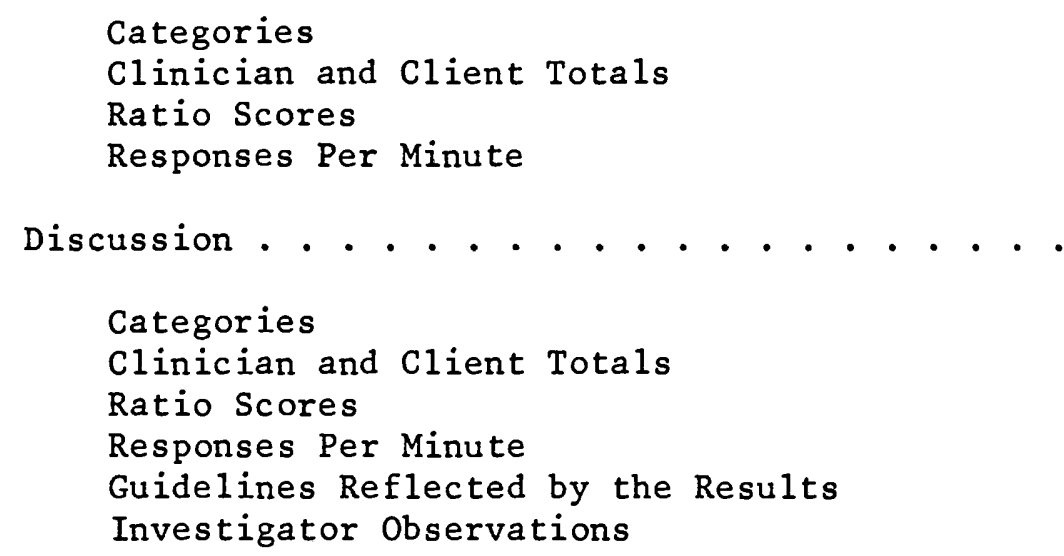

Categories

Clinician and Client Totals

Ratio Scores

Responses Per Minute

Guidelines Reflected by the Results

Investigator Observations

Categories

Clinician and Client Totals

Ratio Scores

Responses Per Minute

Research Implications . . . . . . . . 55

Clinical Implications ......... . 56

BIBL IOGRAPHY

APPENDICES

A REVISED TEN-CATEGORY SPEECH AND HEARING THERAPY SESSION SCORING FORM . . . . . . . . . . .

B STECH 10 CATEGORY INTERACTION ANALYSIS SYSTEM . . . . 62

C PRESCOTT 19 CATEGORY INTERACTION ANALYSIS SYSTEM . . .

D BOONE-PRESCOTT CONTENT AND SEQUENCE ANALYSIS SYSTEM ................ 65

E INFORMED CONSENT . . . . . . . . . . . . 66

F PERMIT FOR PHOTOGRAPH/VIDEO ........... 67 
viii

APPENDICES

Page

G SAMPLE TRACKING SHEET . . . . . . . . . . 68

H OMNIDIRECTIONAL DYNAMIC MICROPHONE . . . . . . . 69

I LIST OF INSTRUMENTS USED IN THE STUDY . . . . . . . 71 


\section{LIST OF TABLES}

TABLE

Page

I Mann-Whitney U Scores of Categories for Group I and Group II . . . . . . . . . . . . . 31

II Mann-Whitney U Scores of Clinician and Client Totals for Group I and Group II . . . . . . . . . . . 33

II Mann-Whitney U Scores of Ratio Scores for Group I and Group II . . . . . . . . . . . . 35

IV Two-Tailed $t-T e s t$ for Independent Means . . . . . . . 36

$\mathrm{V}$ Scores Reflecting a Trend Towards Good Clinician/ Client Interaction . . . . . . . . . . . . 47 


\section{LIST OF FIGURES}

FIGURE

Page

1 Schematic diagram of the videotaped clinic room setting. . . . . . . . . . . . . . . .

2 Schematic diagram of the videotaped laboratory setting . . . . . . . . . . . . . . . . . 
CHAPTER I

INTRODUCTION AND PURPOSE

\section{Introduction}

In preparation for becoming a competent speech-language pathologist, a student clinician must acquire the knowledge and skill to implement programs to remediate speech, language and hearing disorders. For development of this competency, it has become increasingly important for a clinician to become proficient in the interactive process with clients (Ward and Webster, 1965 ).

The clinician's interactive skills can best be assessed through an evaluation process. Traditionally, it has been the supervisor who subjectively evaluates the clinician-client dyad and provides feedback. The feedback may be in either a written or verbal form, and deals with both the strengths and weaknesses of the interaction process (Culatta, Colucci and Wiggins, 1975).

The supervisor's subjective feedback is a valuable source of information for the clinician in training, as it is based upon past clinical experience and knowledge in the field of speech-language pathology (Ward and Webster, $1965_{b}$ ). It is also very helpful to the student clinician because information and suggestions can be put forth in a way that would best help his understanding. Thus, the supervisor can deal with the clinician's individual difficulties in a way that would best meet his needs (Van Riper, 1965). 
Although subjective views are important to the learning process, there are some disadvantages. Subjective feedback may lack consistency, for the supervisor's attitudes and moods are subject to change as conditions change (Culatta et al., 1975). Furthermore, consistency of evaluation may fluctuate depending upon the ability of the supervisor to observe and analyze the events taking place during the clinic session (Boone and Prescott, 1972a). For the above reasons, professionals and researchers in the field of speech-language pathology have found it necessary to derive more objective means of evaluating the clinician-client dyad (Culatta et al., 1975).

The use of interactional analysis systems has been used to fulfill the need for more objectivity. These systems were originally designed for and utilized in areas of psychology and education and later for use in speech-language pathology (Brookshire, Nicholas, Krueger and Redmond, 1978). Such systems provide a method for systematically recording and analyzing the clinician-client interaction. The Boone-Prescott Content and Sequence Analysis System (B-P) (Boone and Prescott, 1972a), is one of the many formal systems utilizing systematically recording and analyzing techniques.

The $\underline{B-P}$ is a result of modifications of similar systems deve1oped over several years of research. Through its past revisions and uses in research, the systems have been found to be reliable methods for the supervisor and/or student clinician to analyze clinic sessions more objectively, during direct observation, or through videotape or audiotape recordings (Boone and Goldberg, 1969; Prescott, 1970; Boone and Prescott, 1972 $\mathrm{b}$ ). Boone and Goldberg (1969) found their original 
ten category system to help improve reinforcement schedules of student clinicians. The nineteen category system developed by Prescott (1970) proved to be useful for analysis of interaction of a variety of clinical settings as well as denoting similarities and differences among student clinicians' interactive skills (Prescott, 1970; 01sen, 1972).

Although the $\underline{B-P}$ and $i t s$ past "father" systems have been a great asset to evaluation of clinic sessions, information is lacking in regard to the relationship between quality of interactive skills demonstrated by clinicians and the data derived from the behavioral parameters comprised in the ten category Content and Sequence Analysis System (Boone and Prescott, 1972 ).

\section{Statement of Purpose}

The purpose of this study was to determine what type of data derived from the Boone-Prescott Content and Sequence Analysis System is reflected by student clinicians who were rated highly by their clinical supervisors on clinical interaction skills versus students who were rated less favorably by their clinical supervisors on clinical interactional skills. The data analyzed in this study were derived from the parameters listed on a Revised Boone-Prescott Scoring Form. They are: 1) the number and percentage of behavioral events of both the clinician and client, 2) the number and percentage of clinician total responses and client total responses, 3) the number of total responses between clinician and client, 4) the number of responses per minute, and 5) the ratios of designated behavioral events for both the clinician and client, e.g., Correct Response and Direct 
Control (see Appendix A).

This study has addressed the following question: How do $\underline{B-P}$ data compare for clinicians who have been highly rated subjectively with those who have been less favorably rated subjectively by supervisors? 
CHAPTER II

REVIEW OF THE LITERATURE

Roles of the Supervisor

The profession of speech/language pathology has become increasingly aware of the importance for student clinicians to receive quality training in clinical experience. A primary goal is to develop student clinicians into highly qualified individuals capable of independently diagnosing and remediating speech, language and hearing disorders (Halfond, 1964; Matthews, 1966; Darley, 1969; Oratio, 1977). The supervisor, who ideally is knowledgeable in the academic areas as well as skilled in clinical procedures, has been considered to be suitable for the training task.

Although highly aware of the importance of quality supervision, the profession has been unable to define clearly its specific roles and function. As the need for role clarification became known, guidelines were gradually established. Miner (1967) contributes the following insights regarding supervisory roles:

1) Realistic goals should be established with the student clinician which are clearly understood by both student and supervisor.

2) Knowledge and the use of a variety of materials, methods and techniques are to be employed, which are based on sound theory, successful practice or on documented research.

3) The supervisor should recognize and set aside his personal prejudices and biases which could influence 
perception and develop rigidity in order that the subjective task of evaluation may become as objective as possible.

4) The student clinician should be challenged and motivated to strengthen his clinical competency.

The supervisor must be the intermediary person who helps monitor the activities of the student clinician as he applies knowledge learned from texts and classroom lectures to the particular speech/ language behaviors demonstrated by his client. As theory is put into practice and student competency develops, the supervisor should reduce the amount of guidance, thus, enhancing greater independence and autonomous professionalism (Halfond, 1964; Miner, 1967; Oratio, 1977). Villarreal (1964) and Baldes, Goings and Herbold (1975) further added the supervisor should become a model clinician demonstrating and clarifying clinical techniques, as well as teaching clinical content such as scheduling, program planning, record keeping, et cetera. The supervisor's quality model helps the student clinician develop personal clinical skills with greater assurance.

Van Riper (1965), Ward and Webster (1965 $\left.{ }_{a}\right)$, and Brown (1967) also indicated the supervisor has the responsibility of being a counselor, who must recognize individual character differences of their clinicians, so as to lend the appropriate support and guidance that would meet their individual needs. Van Riper (1965) stipulates it is this type of personal interaction that makes "the most impact, helping to turn students into qualified clinicians."

A major function of the clinical supervisor is to observe and provide evaluative feedback concerning the student clinician's interactive skills with the client (Haller, 1967; Miner, 1967; Klevans and 
Vo1tz, 1974; Culatta, Colucci and Wiggins, 1975). The clinical interaction process can best be defined as the sequence of behavioral events that occur between the clinician and client during the management session. It takes into account how the clinician, in response to the client, applies and relays his knowledge of speech/language disorders through gestures and/or verbalizations (Ward and Webster, $1965_{b}$; Boone, 1970). Boone (1970) best describes this interaction as a cause and effect process where behaviors of each individual are not independent from each other, but rather are very contingent upon each other. Supervisor observation and evaluation of this interactive process are essential if both clinician and client behaviors are to be improved (Boone, 1970; Oratio, 1977).

To ensure and strengthen the training program in all areas discussed, the American Speech-Language-Hearing Association stipulates the following guidelines: A1l clinical supervisors should hold the ASHA Certificate of Clinical Competence or have the equivalent qualifications. Also, the number of hours and places where supervised experience can be obtained has been stipulated. Further specifications indicate at least one-fourth of the clinical practicum must be directly observed by the supervisor (ASHA, 1980).

In summary, the profession of speech/language pathology has striven to identify supervisory roles to help ensure that student clinicians receive the proper training to become highly qualified professionals. These roles can best be defined as coordinator, facilitator, encourager, reinforcer, moderator and evaluator (Anderson, 1974). 


\section{Clinical Observation}

Supervisor observation of the clinic session can be direct or indirect. Direct observation takes place in the clinic room or behind a one-way mirror using earphones or a speaker to provide the auditory feedback (Van Riper, 1965). Indirect observations are made through viewing a videotaped replay of the session (Boone and Goldberg, 1969). Supervisors widely incorporate both these methods for direct observation of student clinicians.

\section{Clinical Evaluation}

Various techniques and criteria have been utilized by supervisors to evaluate the clinician-client dyad. The most common method of evaluation has been subjective, whereby supervisors make intuitive judgements, based upon past experience and an in-depth knowledge of speech/language disorders (Ward and Webster, 1965 ; Klevans and Voltz, 1974). During the clinic session, mental and/or written notes are taken about the interactional behaviors taking place. Following the session, the supervisor provides the student clinician with written and/or verbal feedback consisting of comments and suggestions about the success of the clinic session (Van Riper, 1965). Supervisors also provide this feedback following a series of clinic sessions at individual conferences scheduled throughout the clinician's practicum (Halfond, 1964). These conferences offer help to students and enable them to gain insight as to their strengths and weaknesses in various clinical situations.

The importance of this subjective evaluational feedback must not 
go unrecognized. Van Riper (1965) and Ward and Webster $\left(1965_{b}\right)$ contended supervisor subjectivity provides a means by which comments and suggestions can be denoted suitable to meet the individual character needs of the student clinician.

As another method for clinical evaluation, Halfond (1964) and Prather (1967) recommended group conferences for providing the student clinician with valuable feedback. Here, the supervisor and/or other student clinicians observe and critique the clinic session. Later, the group shares and discusses their observations, providing comments and suggestions. Halfond (1964) believes this procedure provides a "double strength" method of clinician education.

Although subjective means of evaluating the clinician-client dyad has been valuable to the training process, the need for more objective methods of evaluation has become increasingly recognized (Miner, 1967; Kunze, 1967; Baldes et al., 1975; Culatta et al., 1975). A questionnaire study conducted by Rees and Smith (1967) revealed student clinicians were dissatisfied with the present methods of subjective evaluation. In support of these results, Klevans and Voltz (1974) found students were often unsure about what behaviors needed changing, as well as being perplexed about their status in relation to the competency level expected of them by their supervisors.

Miner (1967) recognized the possibility of opinions, personal convictions, biases and prejudices being influential factors in supervisory feedback. Rather than recording and evaluating impressions of observed clinical behaviors, Kunze (1967), Boone (1970) and later Klevans and Voltz (1974) recommended that systematic methods of 
recording and analyzing observed behaviors be utilized. Such methods would help the observer as well as the student clinician become aware of behavioral events, for later modification, if necessary.

Klevans and Voltz (1974) suggested the following criteria be included for an effective objective recording and analyzing system: 1) derived information should be concise, 2) focus on the individual's specific and observable behaviors, and 3) pertain to only those behaviors over which the clinician has some control. In lieu of these criteria, various forms and scales have evolved, in an attempt to evaluate more objectively the clinic session.

Brown (1967) designed an evaluation form in which a variety of clinical attributes could be judged. Categories include personal characteristics and diagnostic methods, as well as management behaviors and progress. The evaluation forms are discussed in a seminar so the students understand what is expected of them.

Boone (1970) developed a charting procedure to record the client's behaviors only. The client's responses are charted continuously over a designated period of time to determine the number of correct and incorrect responses. The clinician can determine the client's progress over a period of time and thus, modify management procedures when necessary.

The Practicum Evaluation Form developed by Klevans and Voltz (1974) describes specific clinician behaviors thought to be essential to the clinical interactive process. The form provides a method for rating the interactive behaviors as being superior, intermediate or minimally effective. 
Other methods to observe objectively and evaluate behavioral events have been through the use of audiotape and videotape replay, closed circuit television and kinescope filming ( $O^{\prime} N e i l l$ and Peterson, 1964; Boone and Stech, 1970; Ryan, 1970; Carnese, 1977). Boone and Stech (1970) noted the following advantages for their use in clinical training: 1) immediate and continuing re-usable playback, 2) stop framing capability, and 3) preservation of the intervention sessions as long as needed. Irwin and Nickles (1970) further added that the comments can be made by the clinical supervisor at the time a behavior is observed without distracting those involved in the management session.

Methods such as those previously described have attempted to evaluate objectively the clinician-client interaction. However, some elements within this evaluation process are undeniably subjective (Klevans and Voltz, 1974). Although these authors have suggested this is inevitable and probably desirable, the profession has continued to seek better objective evaluation tools. The design of interactional analysis systems has been a step towards improving this objectivity (Oratio, 1977).

\section{Interactional Analysis Systems}

Interactional analysis systems are a means to observe objectively and evaluate the sequences of behavioral events occurring between two people (Clare, 1975; Falsey and Ramsey, 1977; Oratio, 1977). The assessment is made on a basis of a code system, each code specifying a type of behavior. Recording of behavioral events may be made during 
direct observation, audiotape or videotape recording, for immediate analysis or analysis at a later time. These descriptive instruments are currently the most useful means of objectively quantifying and analyzing the behavioral events between two people (Amidon and Hough, 1967 ; Oratio, 1977).

Interactional analysis systems were first utilized in the fields of psychology and education, and later adapted for use in speech/ language pathology. Bales (1950), believed to be the founder of interactional systems, devised a method for quantifying the events between pairs of individuals in psychological counseling settings. Numerous systems have been designed to evaluate teacher interaction within the classroom (Hughes, 1959; Flanders, 1960; Amidon and Hough, 1967; Moskowitz, 1967; Buckholdt and Fitzhenry-Coor, 1973). The most widely used system among educators has been the Flanders Interactional System developed by Flanders (1960). This ten-category system quantifies both direct and indirect verbal behaviors of the teacher and pupil. It appears the interactional analysis systems utilized in speech pathology have been designed upon the Flander's (1960) model. These systems offer the supervisor and/or clinician a means to record objectively and evaluate the observed clinical behavior.

Johnson (1969) developed a multidimensional forty-category system in an attempt to describe both verbal and non-verbal clinical transactions. However, low inter-judge reliability coefficients appear to 1 imit the effectiveness of its use because the categories allowed for subjective value judgements. A second system developed by Stech (1969) was used by Boone and Goldberg (1969) to study the 
acquisition of behavioral principles during videotape self confrontation. This ten-category system, comprised of five clinician-centered categories and five client-centered categories, proved to be a reliable, more objective approach to describe the clinical dyad (Boone and Goldberg, 1969; Prescott, 1970). This system was later modified to a similar ten-category system known as the Boone-Prescott Content and Sequence Analysis System (

Another interactional analysis system utilized in speech/ language pathology is the Analys is of Behavior of Clinicians System (ABC) developed by Schubert, Miner and Till (1973). The system is time-based, and utilizes twelve categories for recording behavioral events. The clinician's actions are described in the first eight categories and the client's behaviors are described in categories nine through eleven. The final category, silence, is utilized when the clinician and the client display no verbal or relevant motor behavior. During an evaluation, numbers corresponding to the particular action of either the clinician or client are recorded in three-second interva1s (Schubert and Laird, 1974; Clare, 1975).

Methods for analyzing clinical behaviors further expanded with the development of the Conover Analys is System (Conover, 1974). This system utilizes eleven categories to record relevant verbal and nonverbal clinician-client interactions. Seven categories pertain to clinician responses and four categories pertain to client responses. Letters rather than numbers are recorded as each verbal behavior occurs.

Kaplan and Dreyer (1974) developed a multidimensional interac- 
tional analysis system to measure change in clinician-client behaviors after clinicians have been trained to become aware of their interactive behaviors in the clinic setting. Categories include verbal and nonverbal responses and pertain to areas of social support, facial expression, gestures and amount of verbalizations occurring between the two individuals.

In meeting the needs to find more objective means for recording clinician-client interactive behaviors, interactional analysis systems such as those described above have been used widely in the clinical setting. Although varying in style, method of recording and analysis, they all serve in helping the observer become aware of behaviors transpiring in the clinic setting. This awareness has proven to be successful in helping the clinician improve his interactive skills (Boone and Stech, 1970; Kaplan and Dreyer, 1974; Oratio, 1977). For purposes of this study the Boone-Prescott Content and Sequence Analysis System $(\underline{B-P})$ will be discussed in more detail.

The $\underline{B-P}$ is a modification of a ten-category system originally developed by Stech (1969) for use in a study performed by Boone and Goldberg (1969) (see Appendix B). The system was developed as a means for objectively describing the behavioral events occurring with in the clinician-client dyad free from observer bias, background or experience. This type of methodology remained throughout the systems' modifications. Prescott (1970) expanded the ten-category system to a nineteen-category system in which twelve categories pertain to the clinician's behaviors and seven categories pertain to the client's behaviors (see Appendix $C$ ). Prescott believed the expanded matrix 
system provided a more complete description of the intervention process.

In a later study, Boone and Prescott $\left(1972_{a}\right)$ condensed the Prescott System to form the Boone-Prescott Content and Sequence

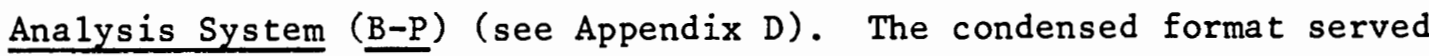
to record the interactions more efficiently. It is also a tencategory system comprised of five clinician-centered categories and five client-centered categories. The matrix is based upon a coding system, in which a number pertaining to the described events are decoded as they occur. For example, a number 3 (Good Evaluative) would be decoded for every observed positive reinforcement (verbal or non-verbal) given by the clinician. The system may be utilized within any middle five-minute period of the clinic session (Boone, 1970; Olsen, 1972).

For purposes of interpreting the behavioral events, the BoonePrescott Scoring Form was developed (Boone and Prescott, 1972 a). The scoring form summarizes the total number of events of each category, as well as lists the number of certain behavioral sequences. Also, a ratio of specified sequential events can be determined, indicating the percentage of correct responses, incorrect responses, good evaluatives, bad evaluatives, inappropriate responses, direct control (by the clinician), and socializations (by both the clinician and client). Later the Portland State University Speech and Hearing Sciences Program included the Response Per Minute section, to indicate the number of responses made by the client during a five-minute segment of a clinic session (see Appendix A). 
The $\underline{B-P}$ has been found to be an effective device to describe objectively the interactional behaviors of clinician-client dyad (Boone and Prescott, $1972_{b}$ ). Through a quantifiable method of analyzing the clinic session, an observer can become more aware of what the clinician and client are doing during management.

It appears there have been limited studies delineating the beneficial factors that can be derived from the utilization and analysis of the $\underline{B-P}$ or its past "father" systems. The ten-category system utilized in the study by Boone and Goldberg (1969), the nineteencategory system developed by Prescott (1970) and the revised tencategory system all have proven to be reliable means to observe objectively and analyze the clinician-client dyad (Boone and Prescott, $\left.1972_{b}\right)$. The interactional analysis systems can be used during direct observation or through videotape or audiotape recordings (Boone and Stech, 1970; Boone and Prescott, 1972 ). Both supervisors and/or clinicians can learn to score reliably the management session (Boone and Goldberg, 1969; Prescott, 1970; Boone and Prescott, $1972_{b}$ ).

The following are specific results derived from the usage of the systems. In using the ten-category system developed by stech (1969) to provide feedback to student clinicians about their interactive behavior, Boone and Goldberg (1969) found student clinicians developed a better awareness of their reinforcement schedule during management. Consequently, positive and negative reinforcement altered from 100 percent and 0 percent respectively to a directional movement of 50 percent for each type of reinforcement.

Prescott (1970) utilized his nineteen-category system to study 
the interaction of both experienced and inexperienced clinicians during intervention with clients representing the four speech-language disorders of voice, language, articulation and prosody. Results of this study indicate the matrix system can be used to determine statistically the presence or absence of differences among clinicians relative to the amount of time behaviors occur (Prescott, 1970). Differences were noted among all subjects for each of the following categories: Explain/Describe, Positive Reinforcement (Social Verbal), Correct Response, Incorrect Response and Inappropriate Response.

In a similar study utilizing the Prescott System, 01sen (1972) also studied inexperienced and experienced clinicians in the four communication disorder parameters of articulation, delayed language, prosody and voice. Based upon descriptive analysis, he found differences in behavior among the four parameters of management studied within clinician groups and differences between experienced and inexperienced clinicians within any given parameter. More specifically, both inexperienced and experienced clinicians differed in their method of reinforcement for their adult and child clients. Primarily nonverbal and verbal reinforcements were used for their adult voice and prosody clients while tangible reinforcements were used for their child articulation and language clients. Also, voice clinicians and prosody clinicians appeared to favor a ratio of 90 percent correct responses while language clinicians and articulation clinicians seemed to favor 70 percent to 75 percent correct responses from their clients. When comparing interactional behaviors of inexperienced and experienced clinicians within the communication disorder parameters, differ- 
ences were noted; however, no general trends could be reported.

Later, Hanlan (1980) utilized the Boone-Prescott Content and Sequence Analysis System to determine if differences existed in scores of clinician-client interactions when rated during live observations or rated during videotape observations (both overtly and covertly). Results indicated there were no differences in scores of clinicianclient interactions among the three situations.

The development of these interactional analysis systems and studies contributing to their use has provided better opportunities to improve clinical management effectiveness as well as conditions under which management can be studied.

\section{Summary and Implications}

The importance for appropriate methods of observation and evaluation of the clinical interactive process increasingly has become recognized within the profession of speech/language pathology (Van Riper, 1965; Ward and Webster, 1965 ; Klevans and Voltz, 1974; Oratio, 1977). In the past, subjective means of analyzing this interaction has been utilized. Although subjectivity has been found valuable in developing clinical interaction awareness, the need for more objective means of evaluation has been imminent. Interactional analysis systems, such as the Boone-Prescott Content and Sequence Analysis System (Boone and Prescott, 1972 ${ }_{a}$ ') and its previous "father" systems, have served to be reliable and effective methods for an observer to use, for evaluation of the clinic sessions.

Studies of Prescott (1970) and Olsen (1972) helped to establish 
guidelines for clinician effectiveness through the use of the Nineteen Category System. Boone (1970) also contributed to this behavioral guideline by commenting that an effective clinician is one who achieves a 75 to 80 percent level of client responses. He also suggested the animation and personality of the client or clinician, as evidenced by verbal and/or non-verbal actions, can contribute to management success. However, no studies have provided statistical significant guidelines for the amount of appropriate behavioral transactions clinicians should employ to be most effective. It should seem quite advantageous if reliable statistical measures could be derived from an effective yet less intricate interactional analysis system (like that of the $\underline{B-P}$ ) to show further clinician interaction effectiveness. Thus, a better guideline could be obtained for any clinical evaluator in understanding what skills need to be improved upon in order to enhance the effectiveness of the clinic session. 


\section{Methods}

\section{Subjects}

The subjects for this study included twenty student clinicians and their respective clients enrolled in the Articulation and Language Clinic, Fall Term, 1980, and the Articulation and Language Clinics and Urban Language Clinics previous to this date. All clinical practicums occurred at the Portland State University Speech and Hearing Clinic.

Principal participants in the study were two supervisors, both having eight years of supervisory experience. They both hold the Certificate of Clinical Competence in Speech/Language Pathology with the American Speech-Language-Hearing Association.

The group of student clinicians chosen for this study was based upon the supervisors' observations and subjective evaluations of clinicians' interactive skills. From a videotape of five-minute clinic sessions, of thirty clinician-client dyads, the supervisors jointly chose ten sessions in which clinicians were demonstrating the poorest clinical interactive skills (Group I), and ten sessions in which clinicians were demonstrating the best clinical interactive skills (Group II).

Before participating in this study, student clinicians and respective clients who were participating in the Articulation and 
Language Clinic, Fal1 Term, 1980, signed informed consents permitting their possible inclusion in the study (see Appendix E). The clinicians and clients enrolled in the Articulation and Language Clinics and Urban Language Clinics previous to Fall Term, 1980, signed a similar consent form prior to the time of videotaping (see Appendix F). These forms granted the Speech and Hearing Sciences Program permission to use the videotaped sessions for educational purposes.

\section{Instrumentation}

The Boone-Prescott Content and Sequence Analys is System (B-P) was used by this investigator to record the interaction of each clinician-client group. This instrument is comprised of ten behavioral categories, five pertaining to the clinician and five pertaining to the client (see Appendix D). During an evaluation period of five minutes, the sequences of interactional events were recorded numerically in reference to the behavioral categories. For example, if a client made a correct response according to the clinician's instruction, a " 6 " (Correct Response) was recorded. Furthermore, if the clinician followed the client's response with a response of approval, either verbally or non-verbally, a "3" (Good Evaluative) was recorded. The recording of each interactional behavior was done in a vertical order for later analysis (see Appendix G).

A Revised Boone-Prescott Scoring Form was utilized as a means of analyzing the behavioral events (see Appendix A). This form summarizes the number of events and their percentage of occurrence, tallies the total number of responses per minute, as well as 1 ists the number of certain sequential events. The sequential events include the 
client's correct response followed by the clinician's good evaluative $(6 / 3)$, the client's incorrect response followed by the clinician's bad evaluative (7/4), and the client's inappropriate social behavior followed by the clinician's re-explanation or instruction $(8 / 1,2)$.

Various ratios of individual categories are also recorded on the scoring form. The ratios specify the percentage of correct responses, incorrect responses, good evaluatives, bad evaluatives, inappropriate responses (of the client), direct control (by the clinician), and socializations (both by the clinician and client). These calculations provide a concise record of the interactional process.

The equipment used in this investigation included omnidirectional dynamic microphones (Model 635A) (see Appendix H), which were connected via audio connections to the videotape recorder (Model AV-3650) (see Appendix I). The videotape used was a standard one-half inch Sony brand.

Investigator Reliability

This investigator was trained in the use of the Boone-Prescott Content and Sequence Analysis System $(\underline{B-P})$ by observing and recording interactions of five-minute clinic sessions when viewed from a videotape. Following training, inter-judge reliability was determined when this investigator's coding was compared with the coding of two supervisors holding the Certificate of Clinical Competence. Both are competent in the use of the $\underline{B-P}$, having performed such analyses on several individuals per term for the past five years. The investigator and two supervisors simultaneously, but independently, viewed and recorded clinician-client interactions from ten one-minute tapes. 
Following the session, results from the recordings were compared between the investigator and each supervisor using a Spearman Rank Order Correlation to determine inter-judge reliability coefficients. The inter-judge correlation coefficients for each of the videotaped samples were $.99, .97, .95, .97, .89, .95,1.00, .95, .92$, and .93 between the investigator and the first supervisor and .99, .95, .99, $.98, .90, .92,1.00,1.00, .95$, and .93 between the investigator and the second supervisor. Two weeks following the inter-judge procedure, the investigator re-analyzed the sample tapes and reached .98, 1.00 , $1.00, .98, .92,1.00, .97, .96$, and .87 correlation coefficients for intra-judge (test/retest) reliability.

\section{Test Setting}

Twenty-three clinician-client interactions occurred in standard $5^{\prime} \times 7^{\prime}$ clinic rooms located in the Speech Communication Department, Portland State University. These rooms were equipped with a table, chairs and a microphone which was connected via an audio connection to the videotape recorder located in the adjacent observation room. Each observation room was furnished with a one-way mirror and audio connection which permitted the investigator to record each clinic session (see Figure 1). Seven of the clinician-client interactions occurred in a laboratory setting, also in the Speech Communication Department at Portland State University. A table, two chairs and a microphone connected to the audio connection on the tape recorder were also supplied. The videotape machine was positioned approximately ten feet from each clinician-client pair for videotaping (see Figure 2). The experimental setting differed due to a limited number of clinic 


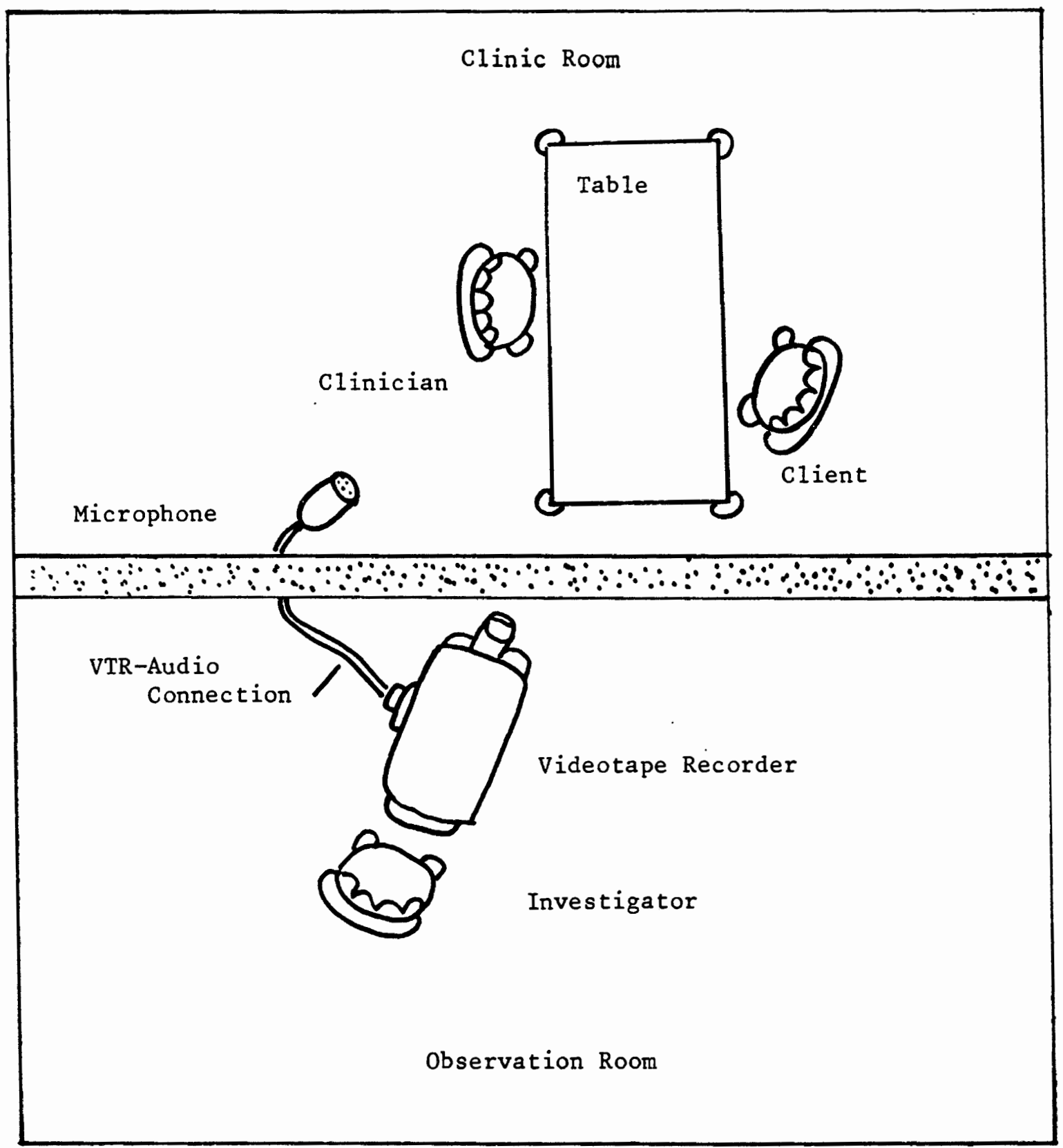

Figure 1. Schematic diagram of the videotaped clinic room setting. 


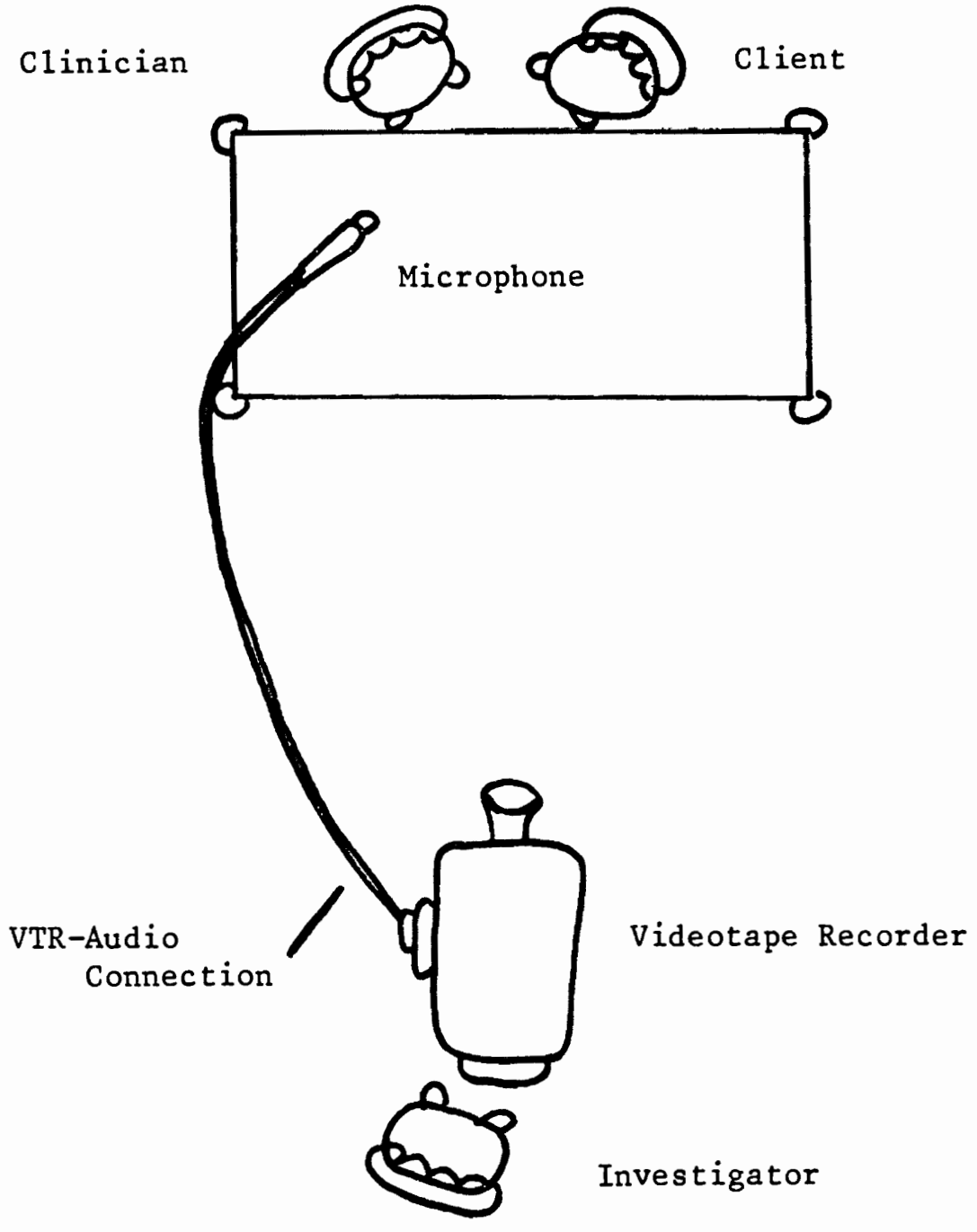

Laboratory Setting

Figure 2. Schematic diagram of the videotaped laboratory setting. 
sessions available for videotaping behind a one-way mirror.

\section{Procedures}

Thirty five-minute videotaped clinical sessions were initially collected by this investigator for the study. Fourteen of these sessions were derived by videotaping dyads of seven student clinicians with each of their two clients enrolled in the Articulation and Language Clinic, Fall Term, 1980. The remaining sixteen videotaped clinical dyads were derived from sessions of student clinicians and their respective clients enrolled in the Articulation and Language Clinics and Urban Language Clinics previous to Fall Term, 1980. Seven of these sessions were videotaped in a laboratory setting. All videotaping occurred during a middle five-minute period within the total fifty-minute clinic period.

After the thirty sessions were compiled, two clinical supervisors viewed each of the five-minute videotaped sessions and chose subjectively ten sessions in which student clinicians were demonstrating the poorest clinical interactive skills (herein labeled Group I) and ten sessions in which student clinicians were demonstrating the best clinical interactive skills (herein labeled Group II). These selected twenty videotaped sessions were used in the study. For purposes of identification and future analyses, the clinician-client dyads within Group I were labeled 1 to 10 and the clinician-client dyads within Group II were labeled 11 to 20.

As a result of collecting fourteen clinic sessions in which seven clinicians interacted with two different clients for the initial 
thirty tapes, supervisors unexpectedly chose eight clinic sessions in the final group of twenty tapes in which four clinicians appeared twice. One clinician appeared twice in Group I (dyads 2 and 5), two clinicians appeared twice in Group II (dyads 11 and 15, and dyads 12 and 20), and one clinician appeared twice, once in each group (dyads 1 and 13).

The supervisors' selection of clinic sessions remained unknown to all student clinicians. The investigator was informed about the sessions chosen; however, the judged skill level of the clinicians remained unknown to the investigator until after the $\underline{B-P}$ analyses were performed. This was to prevent investigator biasing.

Following the supervisors' decision, this investigator observed the twenty videotaped sessions and analyzed the interactions of each clinician-client dyad. The Boone-Prescott Content and Sequence Analy-

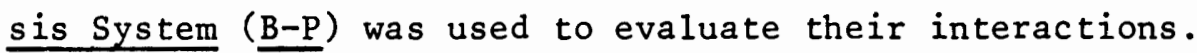

\section{Boone-Prescott Behavioral Recording}

During each videotaped clinic session, this investigator coded clinician-client behaviors using the ten categories in the Boone-

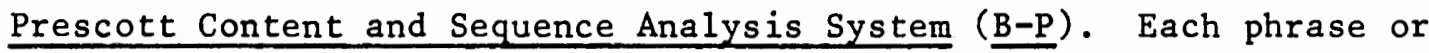
sentence unit was noted as one response (Golper, 1976). Each response was recorded beneath the previous response in columnar style (see Appendix G).

Although many of the responses of both the clinician and client could be applied to the $B-P$, a few types of responses need further clarification. All instructions provided by the clinician to help the client understand his task were recorded as a number 1 (Explain, 
Describe). If the clinician requested the client to evaluate his own response, e.g., "Was that sound correct?" a 2 was recorded (Model, Instruction). A single 2 was listed when the clinician's model was followed by a request, e.g., "The dog is barking. What is the dog doing?" A single 2 was also listed if the clinician's stimulus required multiple responses from the client, i.e., requests for counting objects or naming sequence pictures. All positive reinforcements, e.g., a pat on the back or "You said that nicely," were rated as separate responses and recorded as 3 s (Good Evaluative). The clinician's use of the client's name was recorded differently depending upon the context in which it was used. If the name was used to obtain the client's attention, a number 1 was recorded. A number 2 was 1 isted if the client's name was included as part of the clinician's stimulus. When the client's name was part of the clinician's reinforcement, a 3 was recorded. If the clinician repeated the client's response, a 1 was recorded, unless the repetition was a reinforcement, in which case a 3 was recorded. The clinician's incidental verbalizations such as "uh ha," "That's okay," "um," were recorded as 5s (Neutral, Social) as we11 as all nebulous positive reinforcements and punishments.

Following observation and evaluation of the twenty sessions, the investigator transferred all linear behavioral recordings to a Revised Boone-Prescott Scoring Form where behavioral events and specific behavioral sequences were summarized, responses per minute were computed, and percentages of specified behavioral sequential events were derived (see Appendix A).

After all clinician-client interactional events were recorded 
and summarized on the Revised Boone-Prescott Scoring Forms, data were collected to determine the mean percentages and standard deviations within Group I and Group II for the raw and percentage scores of each category, for the raw and percentage scores of the clinician total responses and client total responses, for the number of total responses between each clinician and client group, for the ratio scores of the Ratio Section and for the number of responses per minute. To determine significant differences between clinician groups a MannWhitney $U$ Test also was performed for each of the above parameters with the exception of Responses Per Minute. A two-tailed t-test for independent means was used for this parameter. 
CHAPTER IV

RESULTS AND DISCUSSION

\section{Results}

This study sought to answer the following question: How do $\underline{B-P}$ data compare for clinicians who have been highly rated subjectively with those who have been less favorably rated subjectively by supervisors? To answer this question the raw and percentage data generated by the less favorably rated clinicians were compared with the highly rated clinicians using the Mann-Whitney U Test (M-WU) for all sections of the Revised B-P Scoring Form except for the response rate data. The $t$-test for independent means was employed to compare the response rate between the two groups.

\section{Categories}

All categories of events were utilized by all clinician-client dyads with the exception of Categories 9 (Good Self-Evaluative) and 10 (Bad Self-Evaluative). Raw and percentage data were derived for each of the eight categories used. Means, standard deviations and MannWhitney $U$ values for both the raw and percentage data are displayed in Table I. Categories which were statistically significantly different were Category 1 (Explain, Describe) for the percentage data, Category 2 (Model, Instruction) for the raw data, Category 5 (Neutral, Social) for the raw data, and Category 6 (Correct Response) for both the raw 


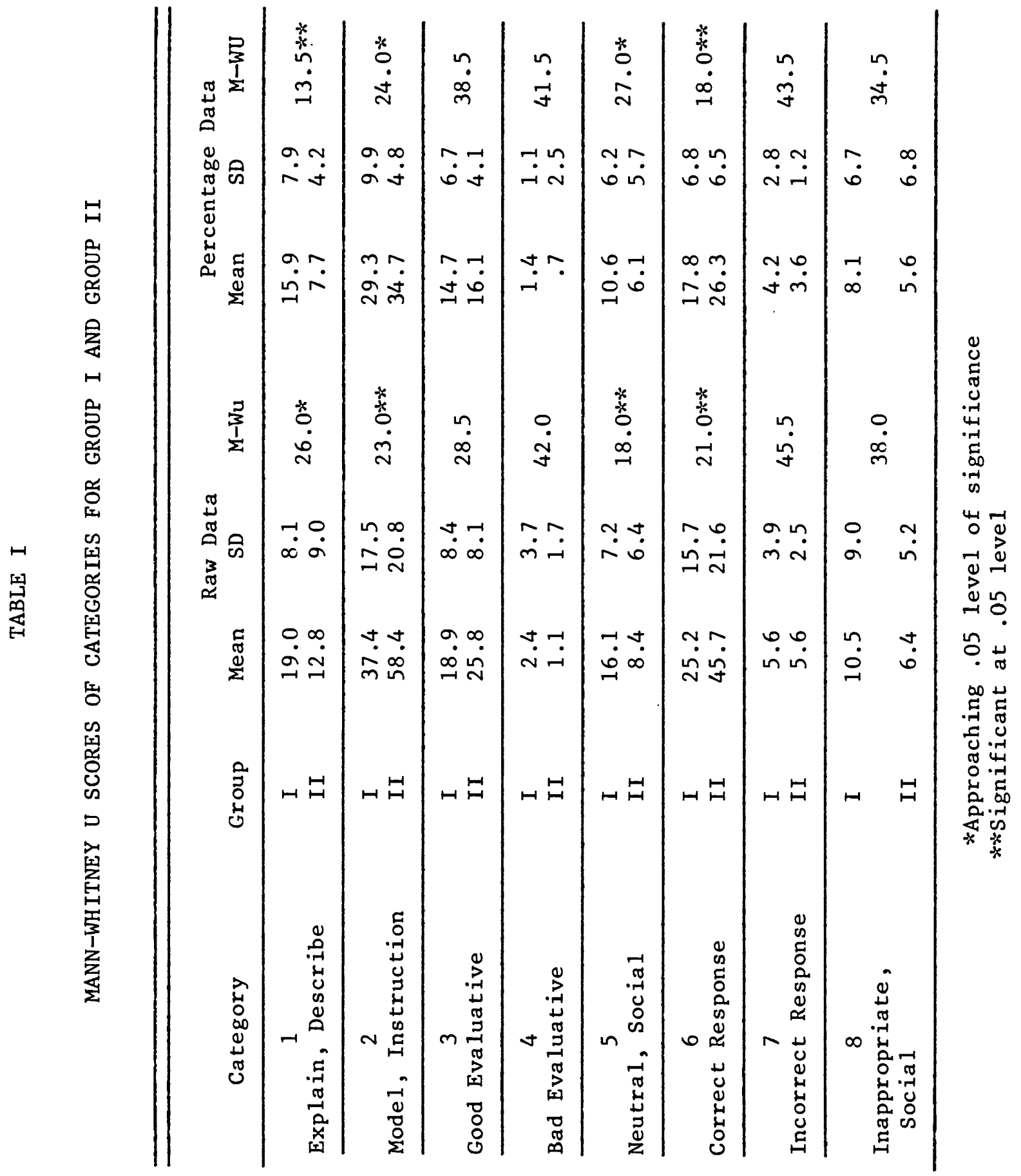


data and percentage data. The direction of significant difference between clinician groups for each of these categories indicates the highly rated clinicians used a lower percent of explanations or descriptions for client tasks, used a higher number of instructional responses, used a lower number of social or neutral responses and elicited a higher number and percent of correct responses from their clients.

Several categories were found to be statistically nonsignificant at the .05 level for raw and/or percentage data. Within this group, however, some differences approached the .05 level of significance, i.e., beyond the .10 level (hereafter noted by "appr."). Categories which were not statistically significantly different were Category 1 (Explain, Describe) for the raw data (appr.), Category 2 (Model, Instruction) for the percentage data (appr.), Category 3 (Good Evaluative) for the raw data and the percentage data, Category 4 (Bad Evaluative) for the raw data and the percentage data, Category 5 (Neutra1, Socia1) for the percentage data (appr.), Category 7 (Incorrect Response) for the raw and the percentage data, and Category 8 (Inappropriate, Socia1) for the raw and the percentage data (see Table I).

Clinician and Client Totals

Raw and percentage data were derived for the Clinician Total section and were found not to be significantly different at the .05 level; however, the percentage data approached the .05 leve1 of significance (see Table II).

Raw and percentage data were derived for the Client Total and 


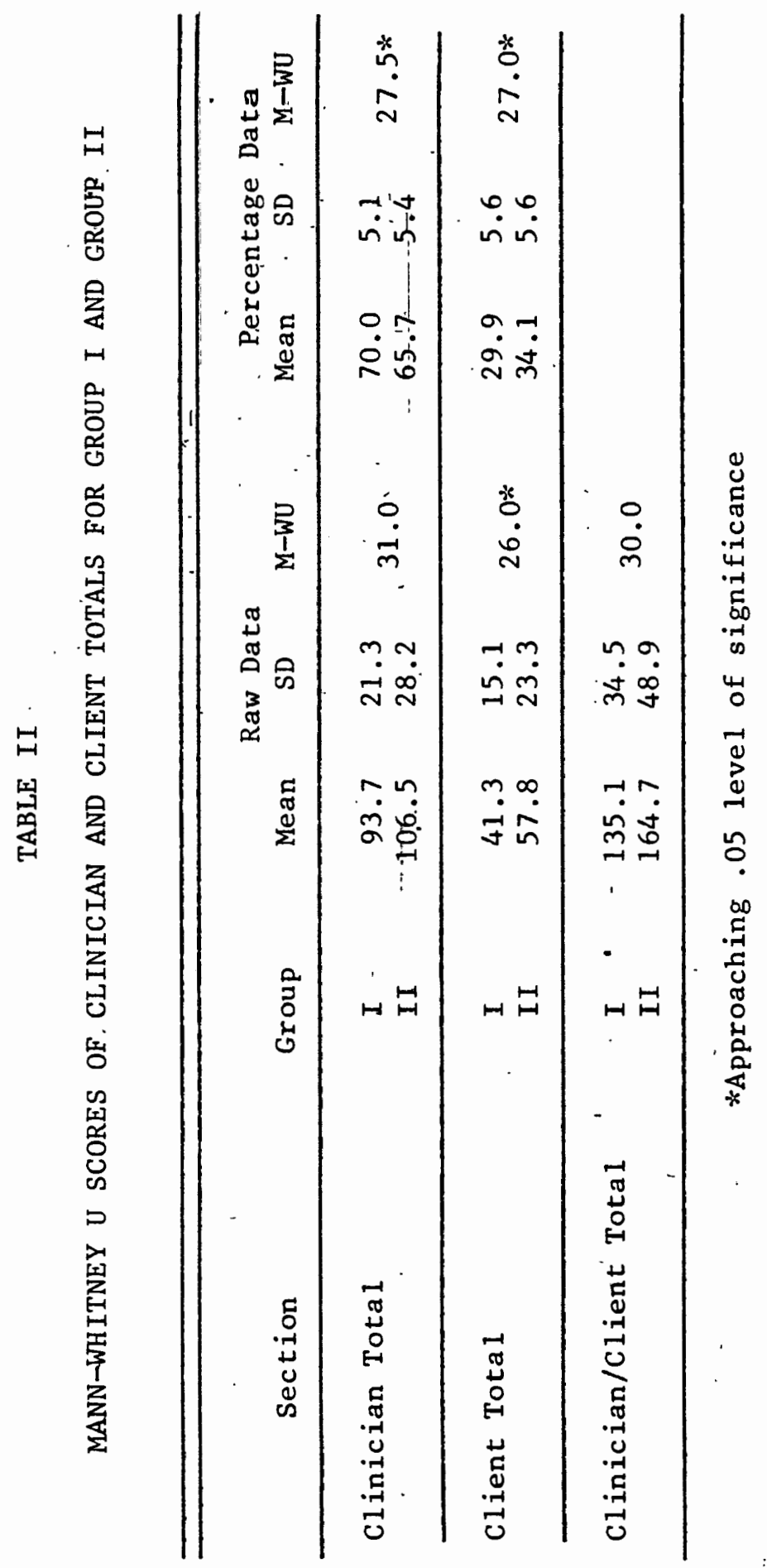


also were found not to be significantly different at the .05 level; however, both the raw and the percentage data approached the .05 level of significance (see Table II).

Raw data were derived from the Clinician/Client Total section of the Revised B-P Scoring Form. The M-WU score indicated no statistically significant difference at the .05 level between Group I and Group II (see Table II).

\section{Ratio Scores}

Ratio scores were derived from the clinician and client responses within Groups I and II. The Socialization ratio was the only ratio showing a statistically significant difference at the .05 level. Clients of higher rated clinicians used a significantly lower percentage of irrelevant responses than did those of the poorer rated clinicians. No significant difference at the .05 level was found for Correct Response, Incorrect Response, Good Evaluative, Bad Evaluative, Inappropriate Response (appr.) and Direct Control (appr.) (see Table III).

\section{$\underline{\text { Responses Per Minute }}$}

A two-tailed t-test for independent means was used to compare the raw data derived from the means of Responses Per Minute between Group I and Group II. The resultant t-score showed the two groups to differ significantly at the .05 level (see Table IV). The higher rated clinicians elicited significantly more client responses than the poorer rated clinicians. 


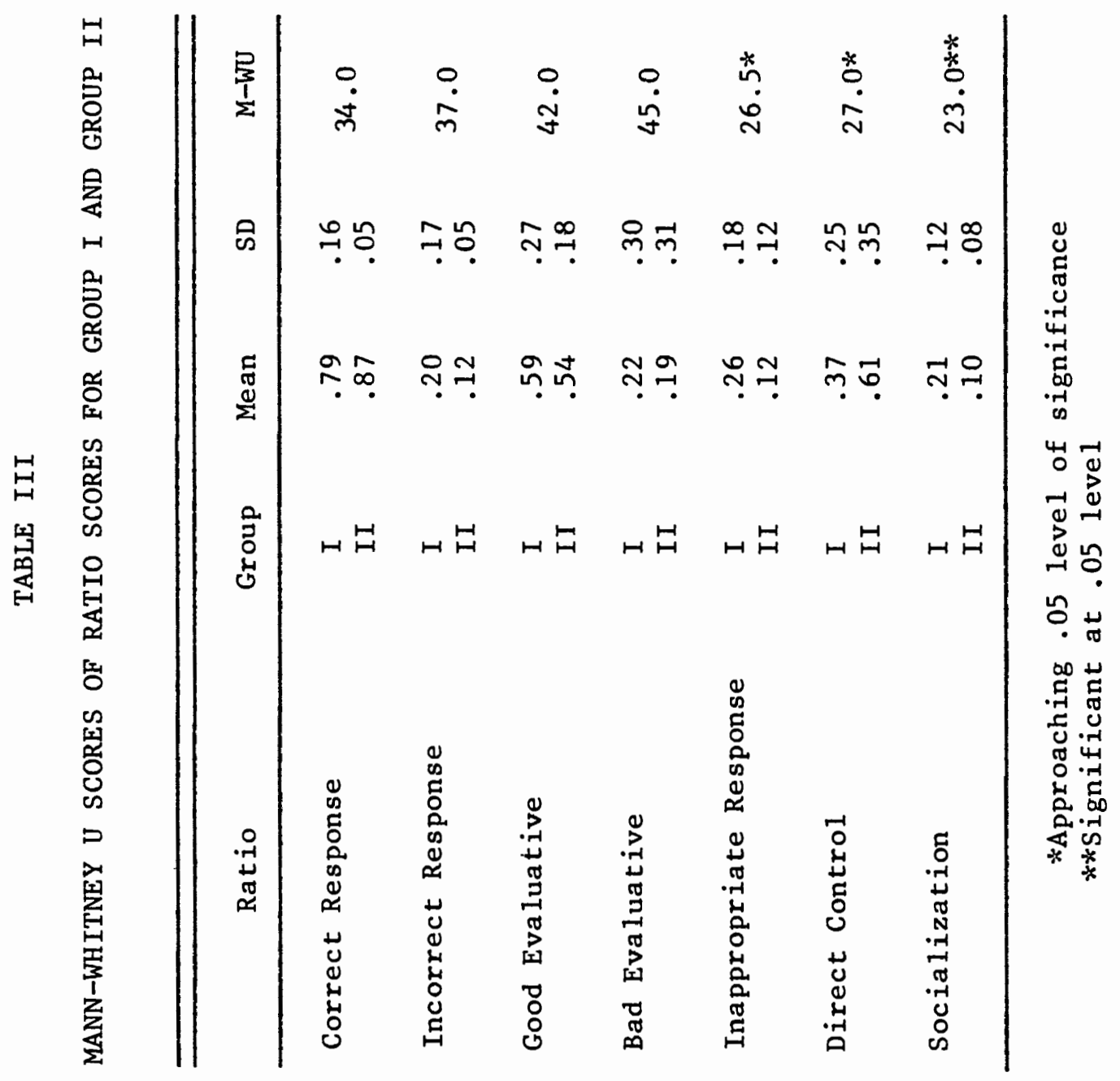




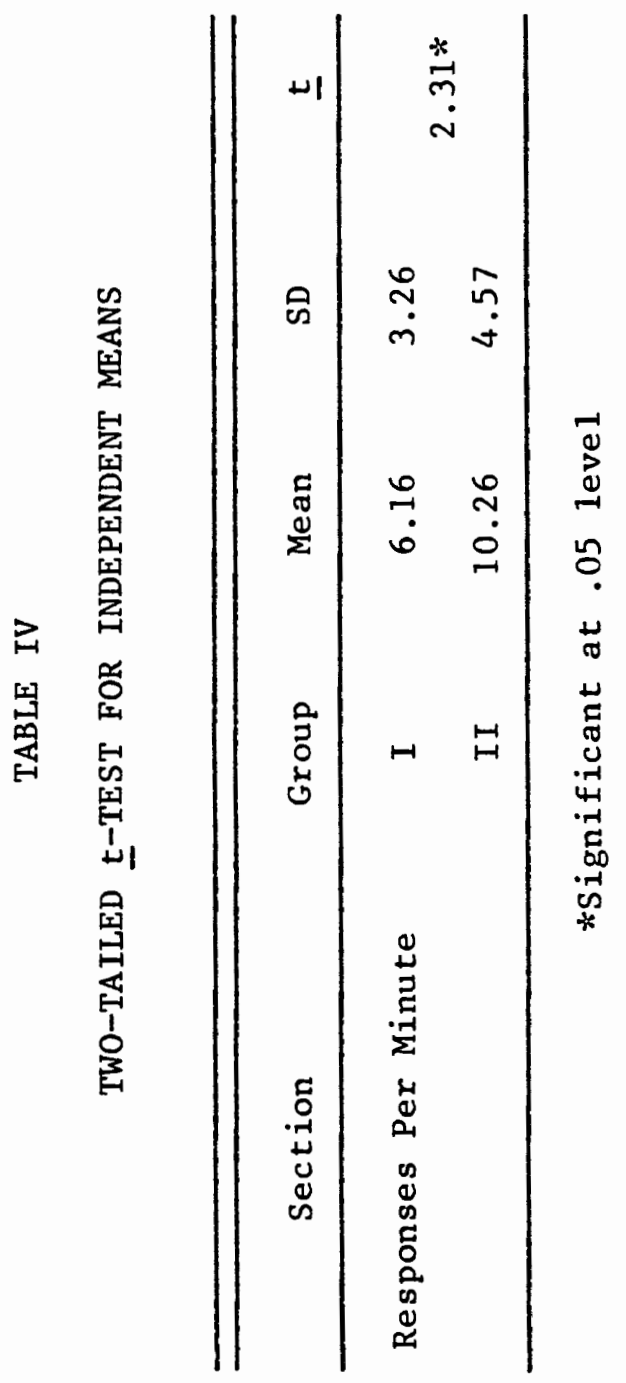




\section{Discussion}

The clinical practicum experience plays a significant role in helping most student clinicians achieve interaction competency. Due to individual differences however, no two clinicians attain competency in the same way and, hence, no two clinicians reflect the same interactional skills. Such differences can be expected among clients as well. Their personalities and reactions to the clinic setting, as well as their differing speech, language and/or hearing problems, will add to the uniqueness of each clinic session. Such differences between both clinician and client may greatly contribute to the variability of interactions within each clinic session. 01sen (1972) noted this variability in behaviors when comparing interactions of inexperienced and experienced clinicians in which no specific trends in differences were indicated. When collecting the raw data, this investigator observed this variability of interactions between individual clinicians and clients within dyads among the same group, and between both groups. The variability also was reflected in the B-P results and may be the reason for few significant differences within its parameters between clinician/client groups.

\section{Categories}

In Category 1 (Explain, Describe) both raw and percentage data reveal that the higher rated clinicians provided less explanation and description of the task than did the poorer rated clinicians; however, only the perkentage data reflect a significant difference. It might be inferred the higher rated clinicians had a better understanding and 
were more familiar with the tasks required of the clients than were the poorer rated clinicians. Results also suggest the higher rated clinicians might have been incorporating more appropriate tasks and using simpler, more precise instructions. Conversely, the poorer rated clinicians may have presented tasks that were too complex for the clients to understand or too difficult for them to perform. Also their explanations for the tasks might have been too lengthy and complex.

Both raw and percentage data in Category 2 (Model, Instruction) reveal the higher rated clinicians spent more time modeling and/or eliciting responses from their clients than did the poorer rated clinicians, although only the raw data are significantly different. From this data, it might be deduced the higher rated clinicians understood the clinical objective and carried it out in a more systematic way than did the poorer rated clinicians. Also, as indicated above, instructions of Group II clinicians might have been more clearly understood (Category 1), leaving more time to elicit client responses. Furthermore, higher rated clinicians might have carried out their model or stimulus more rapidly than the poorer rated clinicians. Results of Category 3 (Good Evaluative) indicate no significant difference between the amount of positive reinforcement employed during the clinic session. Although mean scores were slightly higher for the better clinicians, it can be deduced both groups of clinicians saw the need for and importance of employing positive reinforcement behavior during their clinic sessions. Positive reinforcement is also emphasized in the clinical methods coursework at the Portland State 
University $\mathrm{Clinic}$; hence, the clinicians' behavior might have reflected this philosophy.

Results of Category 4 (Bad Evaluative) indicate a slight difference between Group I and Group II. Both clinician groups employed lower amounts of punishing behavior in response to the greater number and percentage of incorrect responses exhibited by the clients (Category 7). It might be inferred both groups of clinicians either hesitated to correct their clients' incorrect responses by employing nebulous responses for punishment, such as "um," or gave no response at al1.

Raw and percentage data derived from Category 5 (Neutral, Social) indicate the better clinicians engaged in less off-task behaviors than the poorer clinicians. Raw scores specifically reveal a significant difference between the groups. It may be deduced Group II had the discipline to refrain from activities and conversation not pertaining to the objectives of the clinic session. This type of ontask behavior is emphasized by the Portland State University supervisors and the better clinicians reflect this attitude.

The client categories 6 through 8 reflect clinician behaviors as well as client behaviors. Category 6 (Correct Response) yielded raw and percentage data that demonstrated the higher rated clinicians obtained significantly more correct responses from their clients than the poorer rated clinicians. As demonstrated in Categories 1, 2, 3, and 5 , it might be inferred the better clinicians were using their clinic time more efficiently to elicit the desired responses from their clients. For example, the better clinicians provided more 
stimuli to elicit target responses; thus, the clients had more opportunity to respond correctly.

Raw and percentage data essentially did not differ for Groups I and II in amount of client incorrect responses (Category 7). It might be inferred client incorrect responses might have been lower for both groups had the clinicians employed more negative feedback (Category 4), which presumably may have resulted in decreased incorrect responses. It is also possible, if both groups had used easier tasks, the number of incorrect responses would have been less.

Although no significant differences in raw or percentage scores were derived between clinician groups for Category 8 (Inappropriate, Social) clients of the higher rated clinicians used less inappropriate behavior than clients of the poorer rated clinicians. Although differences were not significant, these results would suggest Group II clinicians were more familiar with materials and the specific tasks for the clinic session, and provided more unambiguous explanations (Category 1), straightforward stimuli and/or stimuli at a more rapid pace (Category 2) and used less unnecessary off-task behavior (Category 5). If a clinician was in more control of the session, the client would understand what was expected of him and would have less opportunity to respond inappropriately. Conversely, it is expected clients of poorer rated clinicians would demonstrate more off-task behavior if their clinicians demonstrated more off-target behavior.

\section{Clinician and Client Totals}

Results of scores for Clinician Total responses indicate no significant differences exist between Groups I and II in either the 
raw or percentage data; however, the percentage data indicate an approach towards the higher rated clinicians responding less than the poorer rated clinicians. When comparing these data to the client total responses (in the discussion to follow), both groups responded more than their clients. In studying clinician/c1ient interaction, Boone (1970) also found clinicians employed more responses (especially verbal responses) when interacting with their clients in the clinic session. This is to be expected due to the stimulus-response paradigm of the $2,6,3$ (i.e., stimulus, correct response, positive reinforcement) sequence. This sequence requires the clinician to be active in two-thirds of the events and the client to be active in only one-third of the events.

Although no significant difference was found between clinician groups for client total responses, an approach towards significant difference was indicated for both raw and percentage data, whereby clients of highly rated clinicians responded more than clients of poorly rated clinicians. It might be inferred Group II clinicians were slightly more aware of their verbalizations, hence, gave their clients more opportunities to respond.

No significant difference was found between Groups I and II in the number of total clinician and client responses; however, mean scores indicate the clinic sessions of the higher rated clinicians had more interactions than clinic sessions of the poorer rated clinicians. Scores suggest higher rated clinicians were eliciting responses at a faster rate than were poorer rated clinicians. 
$\underline{\text { Ratio Scores }}$

The Correct Response ratio indicates the percentage of correct responses of the total correct and incorrect responses made by the client. Although both groups achieved a relatively high percentage of correct responses, higher rated clinicians elicited a higher percentage of correct responses from their clients than did the poorer rated clinicians. It should be noted this difference was not statistically significant. It is interesting to note, however, that the mean percentage figure of clients from Group I obtained a more acceptable ratio score according to Boone (1970). He believes the most effective clinician is one who achieves a success rate between 75 percent and 80 percent (as demonstrated by Group I). This percentile level demonstrates the client's task remains challenging, and thus will maintain his/her motivation. However, Olsen (1972) found experienced clinicians varied their criteria for correct responses between 75 percent and 90 percent depending upon the client's communicative disorder. It is this investigator's opinion acceptable percentage scores for correct responses may need to fluctuate above the 75 to 80 percentile range depending upon the needs of the client, i.e., to enhance the client's self-confidence and motivation. Hence, a percentage score higher than 80 percent may be appropriate for some clients (as demonstrated by clients of Group II). Clinical supervisors at the Portland State University Clinic also stress a higher percentage of client correct responses; clients should be performing 80 percent or more. If the client responses are more often correct, it may indicate the terminal objective has been programmed into small, more logically 
sequenced steps.

The Incorrect Response ratio represents the percentage of incorrect responses out of the total correct and incorrect responses made by the client. Although no significant difference was found between groups of clinicians, mean scores indicate clients of the higher rated clinicians emitted a lower percentage of incorrect responses than did clients of the poorer rated clinicians.

Results of the above two ratio scores reflect a reciprocal relationship between percentages of correct and incorrect ratio groups. The more correct responses made from the total correct and incorrect responses, the less percentage of incorrect responses will be made (as demonstrated in Group II). Consequently, less correct responses will be made (as demonstrated in Group I).

The Good Evaluative ratio reflects the percentage of reinforcement the client receives after a correct response is made. Results reflect no significant difference between groups in their sequence of reinforcement for client correct responses. Both groups of clinicians reinforced approximately half of the client's total correct responses. A review of the recorded raw data indicated both groups of clinicians employed continuous and/or variable ratio reinforcement schedules. However, it is this investigator's opinion higher rated clinicians were more aware of their reinforcement schedule because their continuous or variable ratio schedules seemed to be applied more systematically. Conversely, the poorer rated clinicians seemed to lack the reasoning and understanding for applying the schedules because schedules occurred more sporadically. 
The Bad Evaluative ratio reflects the percentage of punishment the client immediately received from the clinician after an inappropriate response was made. Results indicate there is no significant difference between groups. Both groups tended to be lax towards initiating any punishing responses. It may be inferred clinicians were more concerned with rewarding the correct responses (as emphasized in their clinical method coursework) or were either hesitant to correct inappropriate responses and used nebulous remarks or gestures for punishment.

The Inappropriate Response ratio indicates the percentage of off-task behavior engaged by the client from the total number of his correct, incorrect and inappropriate responses. An approach towards significant difference indicates clients of the higher rated clinicians responded more appropriately than did clients of the poorer rated clinicians. It might be inferred Group II clinicians had less difficulty keeping their clients oriented to the specific clinical task. This control is reflected in the results of the ratio scores discussed below.

The Direct Control ratio indicates the percentage of control the clinician has in decreasing client off-target behavior and returning the client's attention back to the clinical task. Results indicate an approach toward a significant difference between clinician groups, in which percentage scores for the higher rated clinicians are higher than percentage scores for the poorer rated clinicians. It might be deduced clinicians of Group II had more control of their clients' inappropriate responses and returned them to the clinical task with 
less difficulty and more consistency than clinicians of Group I. For example, if a client began responding inappropriately, the clinician would say the client's name or "No, let's finish this" or ignore the inappropriate actions and continue eliciting responses (Category 2). Conversely, poorer rated clinicians tended to allow for more inappropriate responses to occur or to participate in the client's off-task behavior before drawing his/her attention back to the clinical task.

The Socialization ratio refers to the amount of off-task behavior engaged in by both the clinician and client during the clinic session. The statistically significant difference found between the higher rated and the poorer rated clinician groups infers Group II clinicians allowed less irrelevant communication in the clinic session. Thus, these sessions resulted in more on-task behaviors and were probably more productive in terms of the clinical objectives.

\section{Responses Per Minute}

Results from the Response Per Minute category indicate the higher rated clinicians elicited significantly more client responses than the poorer rated clinicians. These results directly reflect the results from the Inappropriate Response ratio scores, the Direct Control ratio scores and the Socialization ratio scores. It might be inferred the higher rated clinicians guided their clients towards more on-task behaviors while refraining from much inappropriate behavior. Also, they might have been presenting stimuli and models (Category 2) at a faster pace to give clients more opportunity to respond. 
Guidelines Reflected by the Results

Although few significant differences were found between clinician groups in the above results, several patterns of response behaviors in either the raw or percentage data were found for the higher rated clinicians which differed from the lower rated clinicians.

This author believes the derived data will be valuable for future clinicians to better determine the effectiveness of their interactional skills. For this reason data reflecting the response of Group II are compiled in Table $\mathrm{V}$ for future comparison as a guideline. One should keep in mind however, Table $V$ reflects a behavioral approach towards interactive effectiveness because the supervisors who were chosen initially to evaluate the clinician/client dyads are strongly biased toward a behavioral approach. Also, it must be emphasized that the listed data are only guidelines for appropriate clinical interactional behavior. Differing scores derived from the $B-P$ may be totally appropriate for a particular clinician/client dyad, depending upon the clinic setting and the needs of the client. For example, a low percentage of Direct Control or a high percentage of Socialization may be quite acceptable for a client needing much language stimulation. Thus, it is suggested future supervisors and clinicians reflect upon the reasons and objectives for each clinic session before suggesting or realizing a change in clinician interactive responses (as compared to the guidelines in Table V) is necessary.

\section{Investigator Observations}

As data were gathered and analyzed, this investigator noted several ideas to keep in mind when using the $\underline{B-P}$. Although Boone and 


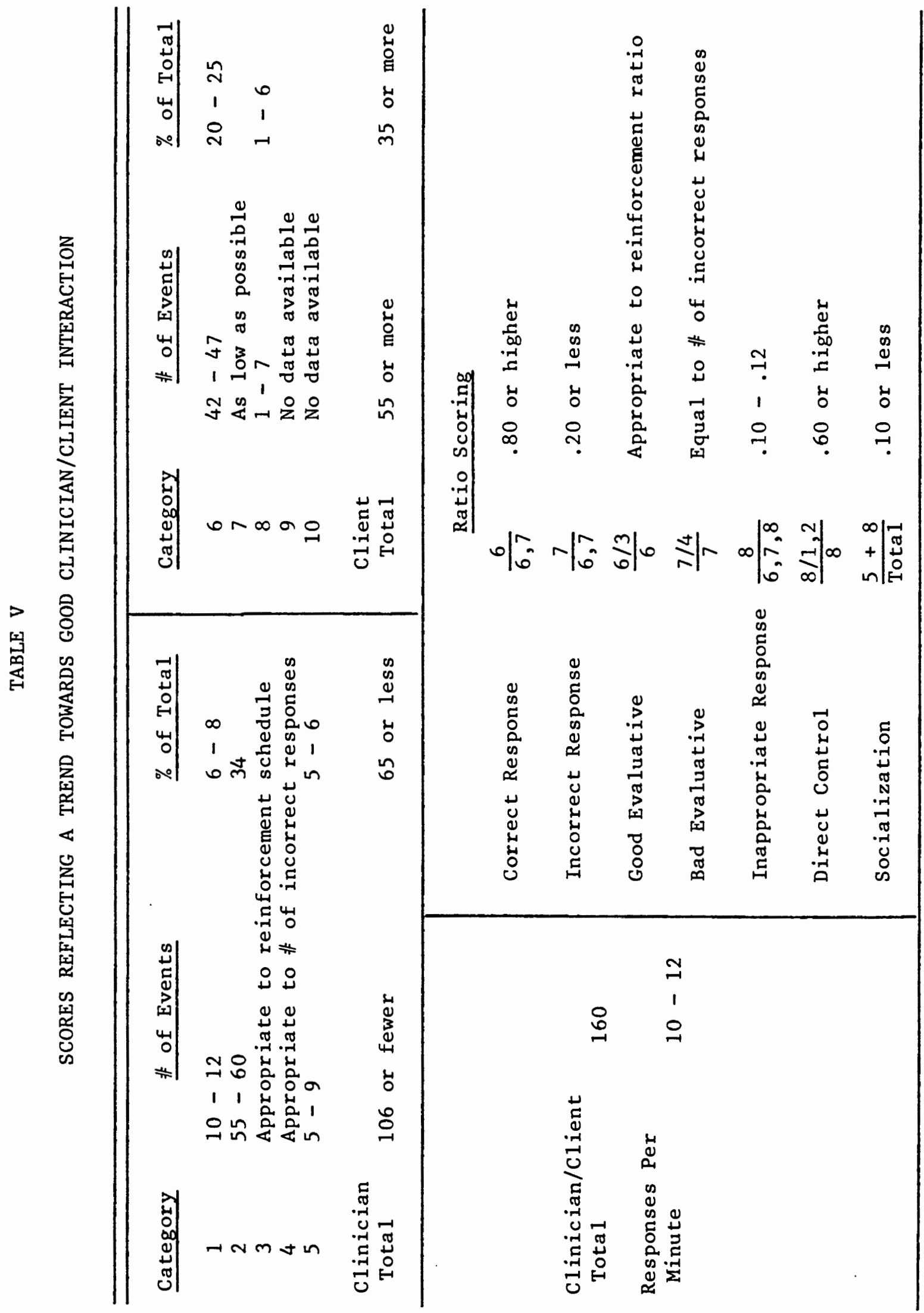


Goldberg (1969) and 01sen (1972) verified that a randomly-chosen middle five-minute segment is a representative sample of the interaction within a clinic session, this investigator questions such stipulations. Often before and after a five-minute sample was taped, this investigator noted changes in both clinician and client behaviors. For example, a clinician might have been providing the appropriate stimulus and reinforcement schedule while controlling the client's inappropriate behavior during the tape recording, yet later in the session would be negligent in applying the stimulus or reinforcement, or allow the client to engage in social, off-task behavior. Based upon these observations, it is recommended supervisors employ the B-P at several five-minute intervals during the clinic session. In this way a more accurate description of the clinician/client interaction could be derived. Although several interactional recordings are recommended for the clinician in training, this investigator believes one middle five-minute recording (as suggested by past studies) would be sufficient for clinicians out of training because their behaviors are assumed to be less variable.

When deriving scores for the Good Evaluative ratio, a few observations also were noted. First, no percentage score can be designated as a guideline for appropriate 6, 3 sequencing (correct response followed by reinforcement) for all clinicians, because reinforcement schedules will alter between and within clinic sessions. Supervisors and clinicians, however, can apply the scores to the individual clinic session to identify how correct the reinforcement schedule is being maintained. Thus, the Good Evaluative ratio is very "individualistic" 
and can be applied as reference to individual clinic sessions.

When listening to the sequence of 6,3 (correct response, good evaluative) responses during recordings of clinician/client interactions, this investigator made further observations. It was noted that, upon occasion, the sequencing of reinforcement was appropriate for the client; however, its reinforcing value appeared to be ineffective. For example, a clinician said "Good" in the same tone of voice for every correct response the client made. This investigator adheres to comments of Ward and Webster $\left(1965_{b}\right)$ when stipulating ". . that success in clinical practice is dependent not only on what the clinician does, but also on how he does it." Reinforcement can have little effect for the client if it remains monotonous. Therefore, it is recommended $5 \mathrm{~s}$ (Neutral, Social) be transcribed during a $\underline{B-P}$ recording if the intended $3 s$ (Good Evaluative) become ineffective for the client. This would help the clinician become more aware of the changes needed to be made when reinforcements are applied in the future.

This investigator believes the $\underline{B-P}$ is a highly useful tool in helping to recognize objectively the strengths and weaknesses of clinician interactive skills. Utilizing the $\underline{B-P}$ can help observers refrain from personal judgements or biases towards the effectiveness of clinician/client interactions within the clinic session. It is highly recommended, however, clinicians in training receive information from this objective feedback system accompanied with subjective feedback from supervisors who have the knowledge and are highly experienced in clinical interactions. Culatta and Helmick (1980) are 
quite supportive of this subjective input in noting that supervision does make a difference in clinician training. Supervisors are more aware of various clinical techniques and materials and can integrate their knowledge to help the clinician in many areas where weakness is shown. They can help the clinician interpret the results of the $\underline{B-P}$ and provide suggestions where change may be necessary. Supervisors can also serve as models and be supportive of the clinician's actions (Prather, 1967; Culatta and Helmick, 1980). Thus, their personal interaction of doing, showing, as well as telling, can help supplement objective feedback and in so doing help the student become a competent professional. Once out of training, the clinician does not receive the supervisory feedback as noted above; however, objective feedback from results of the $\underline{B-P}$ would be valuable. Having been trained in appropriate clinical skills, the clinician could apply the clinical circumstance and the needs of the client to the results of the $B-P$ and hence note where change would be necessary. Thus, this investigator believes the $\underline{B-P}$ is an effective tool to be used both in and out of training. 
CHAPTER V

SUMMARY AND IMPLICATIONS

\section{Summary}

One of the qualifications for being a competent speech and language clinician is to be skilled in interactional procedures within a clinic setting. Such qualities maximize the progress of a client during his/her remediation program. A clinician's interactional skills can only be developed through training whereby one participates in several clinical settings with clients displaying a variety of speech, language and hearing disorders.

Various evaluation methods have been utilized in guiding the clinician towards interactional competency. These methods include both subjective and objective procedures. Although subjective viewpoints have been noted to be valuable for the clinician in training (Miner, 1967; Prather, 1967; Culatta and Helmick, 1980), objective means have been thought to be an essential asset towards evaluating the clinician-client interaction (Culatta, Colucci and Wiggins, 1975). Interactional analysis systems have been designed to provide this objective feedback. The Boone-Prescott Content and Sequence Analysis System $(\underline{B-P})$ is one of several interactional analysis systems utilized to analyze objectively the interactions between clinician and client. Numbers corresponding to specific clinician and client behaviors are recorded sequentially during a middle five-minute segment of a clinic 
session. These raw data are later transcribed to the Revised BoonePrescott Scoring Form for analysis of both clinician and client responses.

Although this system has been found to be an asset towards evaluating the clinic session (Boone and Prescott, $1972_{b}$ ), information has been lacking as to how the data from the parameters of the $\underline{B-P}$ Scoring Form reflect the quality of a clinician's interactive skills. Hence, this investigator sought to answer the following question: How do $\underline{B-P}$ data compare for clinicians who have been highly rated subjectively with those who have been less favorably rated subjectively by supervisors?

To proceed with the study, two supervisors, reflecting a behavioralistic point of view, chose subjectively from a group of thirty five-minute videotaped sessions, ten sessions in which student clinicians were demonstrating the poorest interactive skills (Group I) and ten sessions in which student clinicians were demonstrating the best clinical interactive skills (Group II). Following the supervisors' decision, each tape was analyzed using the B-P.

Results reflect whether significant differences were demonstrated between groups (in either the raw and/or percentage data) for certain parameters 1 isted on the Revised Boone-Prescott Scoring Form: 1) the ten behavioral events of both the clinician and client, 2) the clinician and client totals, 3) the individual ratio scores, and 4) the number of responses per minute made by the client.

Results indicated much variability between the groups for many of the scores. It was inferred, however, that the individual differ- 
ences of both the clinicians and clients influenced the variability; consequently few statistically significant differences were found between groups. The following is a synopsis of the results.

\section{Categories}

Raw and percentage scores were derived from each of the categories with the exception of Category 9 (Good Self Evaluative) and Category 10 (Bad Self Evaluative), which were not used by any of the client subjects. Results for the categories indicated the higher rated clinicians used a lesser percentage of explanation and description for clinic tasks (Category 7), more models and instructions (Category 2), less socializations (Category 5), and elicited more and a higher percentage of correct responses from their clients (Category 6) than did the poorer rated clinicians. The remaining raw and percentage data indicated no other statistically significant differences between groups; however, some data approached the .05 level of confidence.

Clinician and Client Totals

No statistically significant difference was found between groups for the clinician and client response totals; however, an approach towards significant differences was indicated in both the raw and percentage data. For the Clinician Total response section, higher rated clinicians approached significance for having a lower percentage of total responses than the poorer clinicians. Reciprocally, both raw and percentage data derived from the Client Total response section indicated an approach towards significant difference, in which clients 
of the higher rated clinicians responded more than clients of the poorer rated clinicians. For the Clinician/Client Total response section, raw data indicated an approach towards significance for the higher rated clinicians having more total interactions than the poorer rated clinicians.

\section{Ratio Scores}

A statistically significant difference was found for only one ratio score (Socialization) in which the higher rated clinicians had significantly less irrelevant responses than the poorly rated clinicians. Behavioral trends were noted for the remaining ratio scores. Clients of highly rated clinicians emitted a higher percentage of correct responses and a lower percentage of incorrect responses. Both groups of clinicians used approximately the same amount of reinforcement after correct responses were made and were both relatively lax towards applying appropriate amounts of punishment when incorrect responses were made. An approach towards significant difference between groups indicated clients of highly rated clinicians responded more appropriately than clients of poorly rated clinicians. Also an approach towards significant difference between groups was indicated for the Direct Control ratio, in which highly rated clinicians controlled client inappropriate responses and returned their attention back to the clinical task more than the poorly rated clinicians.

\section{Responses Per Minute}

Results indicated highly rated clinicians elicited significantly more responses from their clients per minute than did poorly rated 
clinicians.

Although few sections revealed statistically significant differences between groups, results provided a guideline for more appropriate interactive behavior as demonstrated by the highly rated clinicians. This guideline is thought to be an asset for future supervisors and clinicians when evaluating clinical interaction skills.

\section{Research Implications}

During the conduction of this study the investigator noted areas for further research. It would seem beneficial if a replication of the present study were made utilizing supervisors (as subjective evaluators) who emphasized a different philosophy towards management, i.e., other than a behavioral approach.

A similar study could compare clinicians who had been highly rated subjectively with clinicians who had been poorly rated subjectively, however qualifying the communicative disorder of their clients as having articulation, language, prosody or voice problems. A follow-up study could compare the similarities and differences between poorly and highly rated clinicians between the groups of communicative disorders, i.e., voice and prosody, voice and articulation, voice and language, etc.

Aother study could derive $\underline{B-P}$ data from interactions of experienced clinicians who were ASHA certified and had several years of clinical experience. Their interactional behavior could reflect similar or different behavioral approaches.

All the above research studies could further strengthen the 
guideline set by the present study for identifying more appropriate clinical interactions.

\section{Clinical Implications}

Results of this study indicate supervisors as well as clinicians both in and out of training now have more of a guideline to evaluate interactional competency when using the Boone-Prescott Content and Sequence Analysis System. This guideline suggests clinicians should be less verbal in their explanations and descriptions for clinic tasks and use more models and stimuli at a systematic pace to elicit their clients' responses. Reinforcement should be consistent with the ratio schedule most appropriate to each clinic session and negative feedback should be implemented for all incorrect responses of the client. A score of 80 percent or more correct responses and 20 percent or less incorrect client responses is recommended. This success rate can best be achieved when the clinician is in control of the session, refraining from inappropriate responses, being familiar with the materials and specific tasks required of the client and discouraging all of the client's off-task behavior.

The above synopsis is only a guideline, however. Depending upon the clinical situation and the needs of the client, other clinician behaviors may be more appropriate. Thus, it is recommended supervisors and clinicians first consider the clinician-client situation before recommending any clinician interactional behavior be changed. 


\section{BIBLIOGRAPHY}

American Speech and Hearing Association. State Conference of Professional Affairs (1980).

AMIDON, E. J., and HOUGH, E. G., Interaction Analysis: Theory, Research and Application. Reading, Mass.: Addison-Wesley (1967).

ANDERSON, J. L., Supervision of school speech hearing and language programs-an emerging role. ASHA, 16, 7-11 (1974).

BALDES, R. A., GOINGS, R., and HERBOLD, D. D., Report of the task force on supervision of student speech clinicians. Department of Public Instruction, Special Education Division, Des Moines (1975).

BALES, R. F., A set of categories for the analys is of small group interaction. American Society Review, 15, 257-262 (1950).

BOONE, D. R., A close look at the clinical process. Conference on Supervision of Speech and Hearing Programs in the Schools. Bloomington, Ind.: Indiana University (1970).

BOONE, D. R., and GOLDBERG, A. A., An Experimental Study of the Clinical Acquisition of Behavioral Principles by Videotape Self Confrontation. Final Report. Project No. 4071, Grant No. OEG 8-071319-2814, U.S. Department of Health, Education and Welfare, Division of Research, Bureau of Education for Handicapped, Office of Education (1969).

BOONE, D. R., and PRESCOTT, T. E., Content and sequence analysis. ASHA, $14,58-62\left(1972_{a}\right)$.

BOONE, D. R., and PRESCOTT, T. E., Application of Videotape and Audiotape Self Confrontation Procedures to Training Clinicians in Speech and Hearing Therapy, Part II. Project No, 152310, Grant No. OEG-0-70-4758(607), U.S. Department of Health, Education and Welfare, Division of Research, Bureau of Education for the Handicapped, Office of Education $\left(1972_{b}\right)$.

BOONE, D. R., and STECH, E. L., The Development of Clinical Skills in Speech Pathology by Videotape and Audiotape Self Confrontation. Final Report. Project No. 1381, Grant No. OEG-9-071318-2814, U.S. Department of Health, Education and Welfare, Division of Research, Bureau of Education for the Handicapped, Office of Education (1970). 
BROOKSHIRE, R. H., NICHOLAS, L. S., KRUEGER, K. M., and REDMOND, K. J., The clinical interaction analysis system: A system for observational recording of aphasia treatment. J. Speech Hearing Disorders, 43(4), 437-447 (1978).

BROWN, E. L., A university's approach to improving supervision. ASHA, 9, 476-479 (1967).

BUCKHOLDT, D., and FITZHENRY-COOR, I., A procedure for recording sequential interaction in the classroom. Paper presented at the Annual Meeting of the American Educational Research Association, New Orleans (1973).

CARNESE, T. M., A comparison of the clinician-client interactions in Urban Language $\mathrm{Clinic}$ and Stuttering $\mathrm{Clinic}$. M.S. thesis, Portland State University (1977).

CLARE, S. K., A study of student clinicians' behaviors in response to feedback from the analysis of behaviors of the clinician ( $A B C$ ) system. M.S. thesis, Portland State University (1975).

CONOVER, H., Conover Analysis System. Paper presented at the American Speech and Hearing Association Convention, Las Vegas (1974).

CULATTA, R., COLUCCI, S., and WIGGINS, E., Clinical supervisors and trainees: Two views of a process. ASHA, 17(3), 152-157 (1975).

CULATTA, R., and HELMICK, J. W., Clinical supervision: The state of the art. ASHA, 985-993 (1980).

DARLEY, F. L., Clinical training for full-time clinical service: A neglected obligation. ASHA, 11, 143-148 (1969).

FALSEY, S., and RAMSEY, B., Interactional Analysis: A Procedure for Assessing the DARCEE Preschool Program. Research project, Demonstration and Research Center for Early Education (1977).

FLANDERS, N. A., Teacher influence pupil attitudes and achievement. Pre-publication manuscript of a Proposed Research Monograph. Project No. 397, U.S. Department of Health, Education and Welfare, Division of Research, U.S. Office of Education (1960).

GOLPER, L. D., The efficiency of teaching interaction analysis to students in speech pathology. M.S. substantiated paper, Portland State University (1976).

HALFOND, M., Clinical supervision: A stepchild in training. ASHA, $6,441-444$ (1964).

HALLER, R. M., Supervisors criteria for evaluating students' performance in clinical practicum activities. ASHA, 9, 479-481 (1967). 
HANLAN, J. W., Comparison of videotape observation to direct observation. M.S. thesis, Portland State University (1980).

HUGHES, M., Development of the Means for Assessment of the Quality of Teaching in the Elementary Schools. University of Utah, a Research Report. U.S. Department of Health, Education and Welfare, Office of Education (1959).

IRWIN, R. B., and NICKLES, A. A., The use of audiovisual films in supervised observation. ASHA, 12, 363-367 (1970).

JOHNSON, T. S., The development of a multi-dimensional scoring system for observing the clinical process in speech pathology. Doctoral Dissertation, University of Kansas (1969).

KAPLAN, N. R., and DREYER, D. E., The effect of self-awareness training on student speech pathologists-client relationship. J.Communication Disorders, 7, 329-342 (1974).

KLEVANS, D. F., and VOLTZ, H. B., Development of a clinical evaluation procedure. ASHA, 16, 489-491 (1974).

KUNZE, L., Program for training in behavioral observation. ASHA, 9, 473-476 (1967).

MATTHEWS, J., Essentials of an acceptable program of training for speech pathologists. ASHA, 8, 231-234 (1966).

MINER, A., Standards for quality supervision of clinical practicum. ASHA, 9, 471-472 (1967).

MOSKOWITZ, G., The Flint System (Foreign Language Interaction System): An observational tool for the foreign language class. In A. Simon and G. Boyer (Ed.), Mirrors for Behavior. Philadelphia: Research for Better Schools Inc. (1967).

OLSEN, B. D., Comparison of sequential interaction patterns in therapy of experienced and inexperienced clinicians in the parameters of articulation, delayed language, prosody and voice disorders. Unpublished doctoral dissertation, University of Denver (1972).

O'NEILL, J. J., and PETERSON, H. A., The use of closed circuit television in a clinical training program. ASHA, 6, 445-447 (1964).

ORATIO, A. R., Supervision in Speech Pathology: A Handbook for Supervisors and Clinicians. Baltimore: University Park Press (1977).

PRATHER, E. M., An approach to clinical supervision. ASHA, 9, 472-473 (1967). 
PRESCOTT, T. E., The development of a methodology for describing speech therapy. Unpublished doctoral dissertation, University of Denver (1970).

REES, M., and SMITH, A., Supervised school experience for student clinicians. ASHA, 9, 251-256 (1967).

RYAN, B. P., The Use of Videotape Recording (VTR) on University Speech Pathology and Audiology Training Centers. ASHA, 12, 555-556 (1970).

SCHUBERT, G. W., and AITCHISON, C., A profile of clinical supervisors in college and university speech and hearing training programs. ASHA, 17, 440-447 (1975).

SCHUBERT, G. W., and LAIRD, B. A., Length of time necessary to obtain a representative sample of clinician-client interaction. Paper presented at the American Speech and Hearing Association Convention, Las Vegas (1974).

SCHUBERT, G. W., MINER, A. L., and TILL, J. A., The Analysis of Behavior of Clinicians (ABC) System. University of North Dakota Press (1973).

STECH, E. L., A set of learning theory categories for analyzing the speech therapy situation. A manual for scoring video and audio tapes. Unpublished manuscript. In Boone, D. R., and Goldberg, A. A., (Ed.), An Experimental Study of the Clinical Acquisition of Behavioral Principles of Videotape Self Confrontation. Final Report. Project No. 4071, Grant No. OEG 8-07139-2814, U.S. Department of Health, Education and Welfare, Division of Research, Bureau of Education for Handicapped, Office of Education (1969).

VAN RIPER, C., Supervision of clinical practice. ASHA, 7, 75-77 (1965).

VILLARREAL, J., Seminar on guidelines for supervision of clinical practicum. American Speech and Hearing Association Convention, Washington, D.C. (1964).

WARD, L., and WEBSTER, E., The training of clinical personnel: I. Issues in conceptualization. ASHA, 6, 38-40 (1965 ${ }_{a}$ ).

WARD, L., and WEBSTER, E., The training of clinical personnel: II. A concept of clinical preparation. ASHA, 6, 103-105 $\left(1965_{b}\right)$. 
APPENDIX A

REVISED TEN-CATEGORY SPEECH AND HEARING THERAPY

SESSION SCORING FORM

Clinician:

Client:

Date:

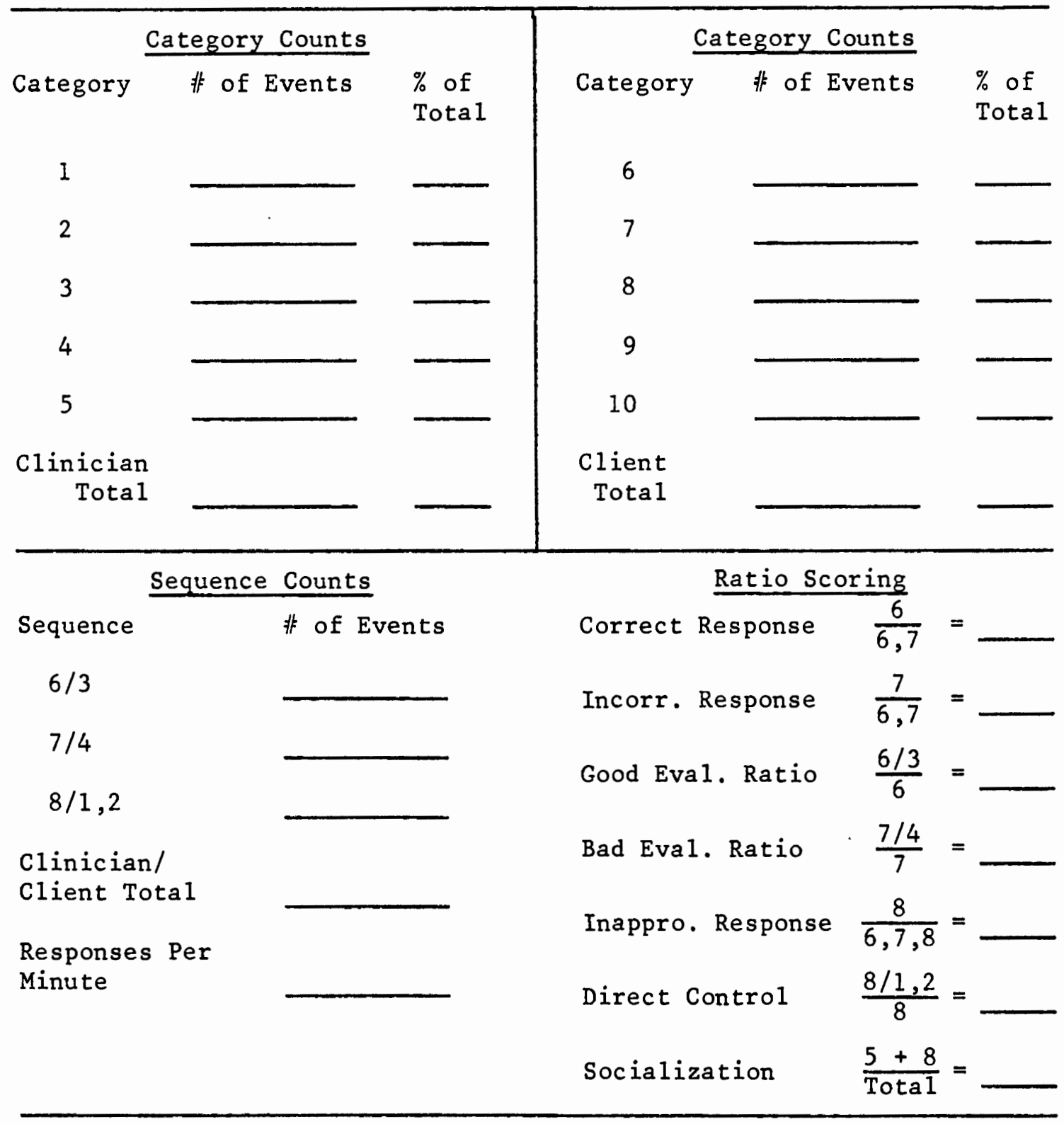


1. Describe, Explain

2. Mode1

3. Positive Reinforcement

4. Negative Reinforcement

5. Neutral and Social

6. Correct Responses

7. Incorrect Responses

8. Inappropriate and Social

9. Positive Self-Reinforcement

10. Negative Self-Reinforcement
Therapist elicits client behavior by description, explanation or by direct control.

Therapist elicits client behavior by direct and conscious modeling.

Therapist positively reinforces the client, either verbally or nonverbally.

Therapist negatively reinforces the client, either verbally or nonverbally.

Therapist engages in activities which do not require client response or which deal with session goals.

Client makes a response which is correct in terms of the therapy goals.

Client makes a response which is incorrect in terms of the therapy goals.

Client makes a response which is not appropriate in terms of the therapist's goals or engages in social conversation not related to the therapy goals.

Client positively reinforces himself by verbally or non-verbally indicating that he considers his response correct.

Client negatively reinforces himself by verbally or non-verbally indicating that he considers his response incorrect. 
APPENDIX C

PRESCOTT 19 CATEGORY INTERACTION ANALYSIS SYSTEM

Category Category

Number Title

Clinician Behaviors:

1. Explain/Describe

2. Presented Auditory Mode1

3. Presented Visual Mode1

4. Presented AuditoryVisual Model

5. Positive Reinforcer (Tangible)

6. Positive Reinforcer (Socia1-Verba1)

7. Positive Reinforcer (Social-Nonverbal)

8. No Observable Reinforcer

9. Negative Reinforcer (Tangible)

10. Negative Reinforcer (Social-Verbal)
Category

Description
Therapist elicits client behaviors by description, explanation, or by direct control.

Therapist elicits client behavior by direct and conscious presentation of an auditory model of the desired behavior.

Therapist elicits client behavior by direct and conscious presentation of a visual model of the desired behavior.

Therapist elicits client behavior by direct and conscious presentation of a combined auditory and visual model of the desired behavior.

Therapist rewards client behavior by awarding a tangible item.

Therapist rewards client behavior by vocalizing approval.

Therapist rewards client behavior by nonverbally indicating approval.

Therapist does not indicate approval or disapproval of client behavior in any manner.

Therapist negatively rewards client behavior in a tangible fashion.

Therapist verbally rewards client behavior in a negative manner. 
Category Category

Number

Title

11. Negative Reinforcer (Socia1-Nonverbal)

12. Neutral/Social

C1ient Behaviors:

13. Correct Response

14. Incorrect Response (Approximation)

15. Incorrect Response

16. Inappropriate/ Social Response

17. Positive Self-Reinforcer

18. Negative Self-Reinforcer

19. No Response

\section{Category \\ Description}

Therapist negatively rewards client behavior by indicating disapproval nonverbally.

Therapist engages in activities which do not require client response or do not deal with the session goals.

C1ient makes a response which is correct in terms of the stimulus presented.

Client makes a response which is an approximation of a correct response in terms of the stimulus presented.

Client makes a response which is incorrect in terms of the stimulus presented.

Client makes a response which is not appropriate in terms of the stimulus presented or engages in social or behavior not related to the stimulus presented.

Client indicates, verbally or nonverbally, that he considers his response to be correct.

Client indicates, verbally or nonverbally, that he considers his response to be incorrect.

Client does not respond, verbally or nonverbally, to the stimulus presented. 
APPENDIX D

BOONE-PRESCOTT CONTENT AND SEQUENCE ANALYSIS SYSTEM

Number Title

1 Explain, Describe

2 Mode1, Instruction

3 Good Evaluative

4 Bad Evaluative

$5 \quad$ Neutral or Social

6 Correct Response

7 Incorrect Response

8 Inappropriate and Social (Irrelevant Behavior)

9 Good Self-Evaluative

10 Bad Self-Evaluative
Description

Clinician describes or explains the specific goals or procedures of the session.

Clinician specifies client behavior by direct modeling or by a specific request.

Clinician evaluates client response and indicates approval verbally or nonverbally.

Clinician evaluates client response and indicates disapproval verbally or nonverbally.

Clinician engages in behavior that is not management goal oriented.

Client makes a response which is correct in terms of the stated management goals, or the clinician stimulus .

Client makes a response that is incorrect according to the stated management goals or clinician request.

Client makes a response or engages in social conversation that is not appropriate to the management goals.

Client indicates awareness of his own correct response.

Client indicates awareness of his own incorrect response. 
APPENDIX E

INFORMED CONSENT

I hereby agree (to serve/let serve) as a subject in the research project conducted by Kathy Noonan, Graduate student, Speech and Hearing Sciences, Portland State University.

I understand the study will involve the videotaping of my clinical management session, however, will not interfere with my regular involvement in the speech-language clinics.

Kathy Noonan has explained there are no possible risks to me associated with the study and the identity of all subject participants will remain confidential. She has also offered to explain any questions I may have regarding my role in the study.

Although I may not personally benefit from participating in this study, I realize my participation may help contribute knowledge which may benefit others in the future.

I understand I am free to withdraw from this study at any time, without jeopardizing my relationship with Portland State University, or with the Department of Speech Communication, Speech and Hearing Sciences Program.

I have read and understand the foregoing information.

Date:

Signature of Participant or Guardian/ Parent If you experience problems that are the result of your participation in this study, please contact Richard Streeter, Office of Graduate Studies and Research, 105 Neuberger Ha11, Portland State University, 229-3423. 


\section{APPENDIX F}

PERMIT FOR PHOTOGRAPH/VIDEO

\section{Date}

Portland State University

Speech and Hearing Clinic

I, , hereby authorize , to photograph/ video tape and release the photographs/video tape for use in: (Cross out those not applicable)

Educational and/or Medical Teaching Programs

Scientific, Medical and Educational Publications

Institutional Promotional Brochures

Non-professional Publications (Newspapers, etc.)

I release Portland State University from any and all responsibility in this connection as stated above. In addition, I (authorize/ do not authorize) the use of my name herewith.

Comments :

Picture No.

Date taken

Photographer/

Technician 
APPENDIX G

SAMPLE TRACKING SHEET

Subject

Session

1
2
6
3
2
6
3
2
6
2
7
4
8
1
2
6
3 


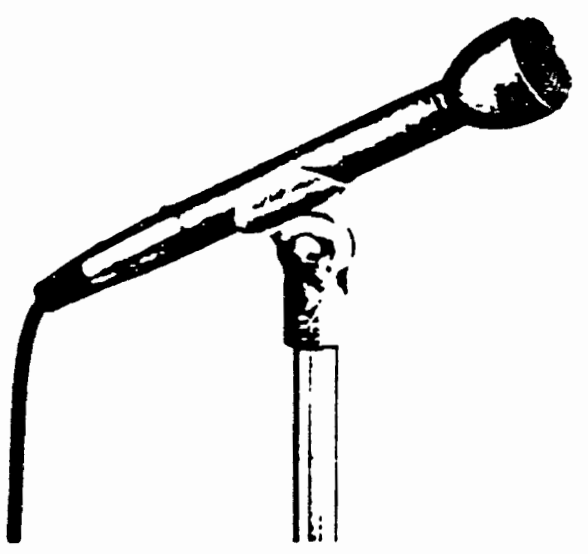

DESCRIPTION AND APPLICATIONS

The E.V model 635A is a dynamuc, omnidirectional mucrophone designed for exacting professional applicasons. and is ideally suted for film production. recording. $F M, A M$, and TV broadcasting, and for the more demand. ing PA applications.

The model 635A is supplied with the model 312A stand adapter The non-reflecting fawn berge mucomatse finash is ideal for "on camera" use. The hich output level and low sensituvity to mechanical shock make it excellent for inter. vews. for pass around use an audience particjpation or for hand-heid use by vocalists.

This microphone features the exclusive non-metallic Electro-Vore Acoustalloy diaphraem which permuts very smooth response over a wide frequency range, and withstands hich humidity and temperature extremes. corrosive effects of alt air, and severe mechanical shocks. It is practically indestructible with normal use.

A four-stage pop and dust fitter insures completely popfree performance and nrtually eliminates the need for an external wndscreen for outdoor use.

Intemal shock absorber effectively reduces pickup of cable and other noise penerated by external contact.

\section{eneifications}

Dewent:

Frequency respone:

Poler Puttern:

impodance:

Output leved:

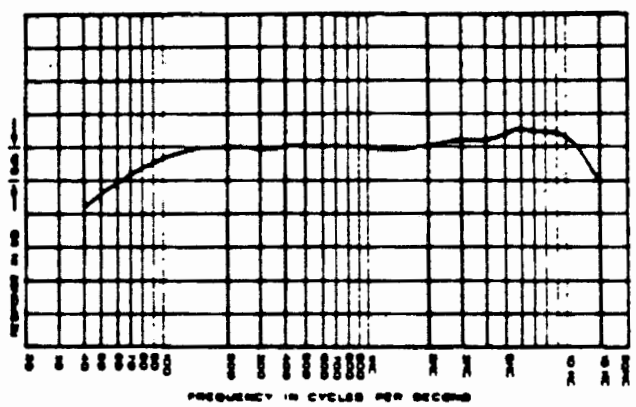

FIGURE 1 - Repones Curve

ELA senativity rating

Diaphram:

Case material

Dimemions:

Finish:

Net Weight:

Switch:

Cable:

Accessories Fumished

Optional Accesories:
$-149 \mathrm{~dB}$

Electro-Votce Acoustallo

Sieel

$5.15 / 16^{\prime \prime}(151 \mathrm{~mm}) 1 . \times 1.13132^{\prime}$

$(36 \mathrm{~mm}) \mathrm{dia}$

Fawn beige micomatie

6 ounces $(1706)$, without cable

None

$15 \cdot(4.6 \mathrm{~m}), 2$-conductor shuelded bradcast type synthenc rubber-jacketed with Smichcraft A3F connector

Mode! 312A Siand Adapier Model 307 Shockmount Model 314 E Windscieen

Mudel 340 Security Clamp Model 342 Security Siud Mount

\section{ARCHITECTS' AND ENGINEERS' SPECIFICATIONS}

The mucrophone shall be an Elecira-Voice model $635 A$ or equivalent. The mucrophone shall be an omnidiectional dyramic type with wide-range response uniform from 80 to $13,000 \mathrm{~Hz}$. It shall have a non-metallic Acoustalloy diaphragm and a fourstace pop filter and magnetic shield to prevent dust and magnetix particles from reaching the diaphragm. The impedance shall be such that the micro phone will match 50, 150, and $250 \mathrm{ohm}$ inputs. The line shall be balanced to ground and phased.
Dynamic

$80-13,000 \mathrm{~Hz}$ Omnidirectional Low (150 ohms)
The output level shall be $-55 d B$ with $O d B$ equalling 1 $\mathrm{mw} / 10$ dynes/ $\mathrm{cm}^{2}$. ElA sensutivity rating shall be -149 dB. The magnetic circuit thall be a nonwelded circuit and employ Anico $V$ and Armeo mapnetic iron. The case shall be made of steel. 
The microphone shall have a maximum diameter of $1.13 / 32^{\prime \prime}(36 \mathrm{~mm})$, and a length of $5.15 / 16^{\prime \prime}(151 \mathrm{~mm})$. and a weight, withous cable, of 6 ar. $(170$ ) $)$. Finish shall De non-eflecting fam beise micomatte. A 15 foor $(4.6 \mathrm{~m}), 2$ conductor shuelded, synthe tic rubber.jacketed, broadcast type cable shall be provided with a Switcheraft ASF or equivalent connector installed. The microphone shall have a bult in connector similas or equivalent to the Switchcraft A3M. The microphone shall include a stand coupler with a 5/8".27 thread. The Electro. Voice Model 635A is specified.

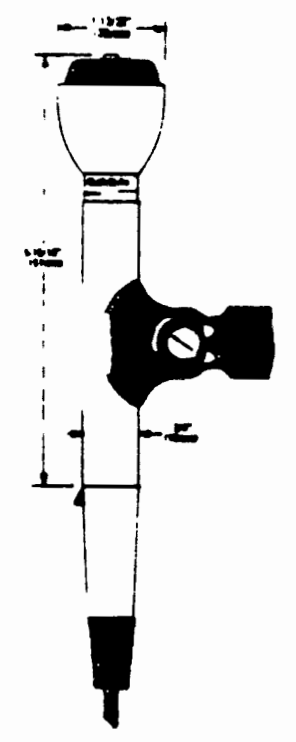

FIGUAE 2 - Dimnaion

\section{WARRAatr (Limitud) -}

Electro.Voice Professional Dynamic Broadcast, Recording, and Sound Reinforcement Microphones are guaranteed unconditionally apeinst malunction from any caus foc a period of 1 wo years from date of orignal purchaxe. Also, every Electro.Voice microphone is guatanteed for the life of the microphone apinst malfunction due to defects in wortemanship and materials. If such mal. function occurs, microphone will be repaired or replaced (at our option) without chate for materials or labor if delivered prepad to the proper Electro-Voice sernce facility. Unit will be retumed prepsid. Watranty does not cover finish, appearance items, cables, cable connectors, or switches and lifetime warranty does not cover mal. function due to abuse or operation at other than spectfied conditions. Repair by other than Electro-Voice or its authorized service apencies will void this purantee.

For correct shipping address, instructions on return of Electro-Voice products for repait, and locations of authorized service arencies. please write: Semce Depart. ment, Electro.Voice, Inc., 600 Cecil Street, Buchanan. Michigan 49107 (Phone 616/695-6831).

Electro-Voice a so maintains complete faclities for nonwarranty service of $E \cdot V$ products.

Specificatsons subject to change without notice.

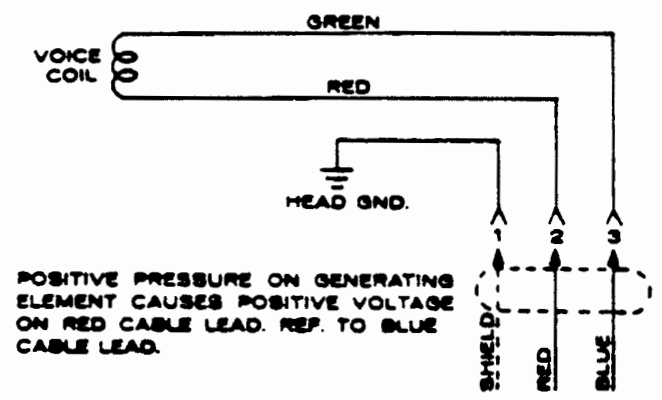

FIGURE 3 - Whing Diegren 


\title{
APPENDIX I
}

LIST OF INSTRUMENTS USED IN THE STUDY

\begin{abstract}
Videotape Replay . . . . . . Sony-Matic AV-3650 ree1-to-reel recorder

Camera . . . . . . . . Sony Camera and Panasonic Camera Monitor

Lens... . . . . . . . TVC Vidicon Zoom $25 \mathrm{~mm}$ to $100 \mathrm{~mm}$ F 1.8

Monitor . . . . . . . Setche11-Carlson T.V. Monitor Model 2100 S.D.
\end{abstract}

